\title{
A Review of Reservoir Operation Optimisations: from Traditional Models to Metaheuristic Algorithms
}

\author{
Vivien Lai ${ }^{1}$. Yuk Feng Huang ${ }^{1}$ - Chai Hoon Koo ${ }^{1}$. Ali Najah Ahmed ${ }^{2}$ Ahmed El-Shafie A,4 $^{3,4}$
}

Received: 8 October 2021 / Accepted: 7 December 2021 / Published online: 25 February 2022

(c) The Author(s) under exclusive licence to International Center for NumericalMethods in Engineering (CIMNE) 2022

\begin{abstract}
Reservoir operation optimisation secures benefits, such as optimising energy production while minimising the possibility of flooding, operating costs, and water scarcity, at the lowest possible cost. This paper carries reviews of research on reservoir optimisation models and the consequential challenges of optimally operating reservoir operations. An introductory section is given to the background of reservoir operations and the current concerns on the optimal reservoir operations, for the decision-makers and stakeholders. Next, the review covered the recent ten years (between 2011 and 2021), on the recent research developments in innovation and techniques of reservoir operation optimisation. Further reviews on the conventional techniques that are the traditional methods, linear programming, nonlinear programming, and dynamic programming are discussed. Enhancements to the techniques in improving the drawbacks of the traditional techniques in optimisation of reservoir policies are next explained and evaluated. Recent advances in applying metaheuristics optimisation algorithms beneficial to the reservoir operations are explained, including the advantages and hinderances. A comprehensive tabulated and categorised review according to the classification of reservoir models, evaluation methods, and reservoir systems is given.
\end{abstract}

\section{Introduction}

Water resource management is an important field of hydrology that also deals with the socio-economic growth in many areas of the world. Water shortage/deficit is a big issue for stakeholders or decision-makers involved with dam/reservoir management. Technology and innovative solutions have more recently been discussed further in depth and adopted to overcome this issue of water usage in river management and operations. Optimising the operations of the reservoir is one of the more advanced ways to circumvent water shortages. Optimisation of reservoir operation management is a set of rules that entails maximising/minimising reservoir benefits without compromising the reservoir's objective functions

Yuk Feng Huang

huangyf@utar.edu.my

1 Department of Civil Engineering, Universiti Tunku Abdul Rahman, Selangor, Malaysia

2 Institute of Engineering Infrastructures (IEI), Universiti Tenaga Nasional (UNITEN), 43000 Selangor, Malaysia

3 Department of Civil Engineering, University of Malaya, 50603 Kuala Lumpur, Malaysia

4 National Water and Energy Center, United Arab Emirates University, P.O Box 1551, Al Ain, United Arab Emirates and constraints. This is often referred to as reservoir operating policy. For example, the key and primary task of the reservoir in irrigation is to satisfy the critical timely needs of efficient water application, whilst conserving water during the rainy season to mitigate floods at the downstream areas can prove to be intuitively challenging. Hydropower generation faces new difficulties when for instance, there is a need to strike a balance between the benefits and the costs associated with environmental regulations, operational constraints, limited capabilities, flow uncertainty, and regulatory constraints [1]. As a result, an effective optimisation algorithm is required to direct and advise the decision-makers in timely fashion on how to handle the multi-objective reservoir operations management. More works are needed because the traditional models, linear programming, non-linear programming and dynamic programming do pose some drawbacks in the general realisation of real-world functional engineering problems [2-5].

This article discusses reservoir optimisation methods that were in use over the last several decades, in a variety of fields, including single- and multi-objective (MO) reservoir activities. It provides a comprehensive review of the host of research topics that had been conducted in the optimisation of reservoir operations, beginning with Traditional models (TS), Linear Programming (LP), Non-Linear Programming 
(NLP), Dynamic Programming (DP), deterministic DP, and stochastic DP, to recent advances in Evolutionary Algorithms (EAs). Due to the lack of the respective approaches and complexity of the reservoir activities, the reservoir models/approaches are then evolved to include recent natureinspired metaheuristics algorithms and other meta-heuristic algorithms (MHAs), culminating to achieve extraordinary degrees of flexibility worthy of pursuing. This review's structure begins with the optimisation innovation and techniques in Sect. 2, followed by some past review studies in Sect. 2.1 to Sect. 4.0. These cover aspects of traditional optimisation techniques, evolutionary techniques, swarm intelligence, hybrid approaches, and finally nature-inspired algorithms. Section 4.1 explains how these techniques are compared in terms of their merits and demerits. Finally, the concluding Sect. 5 also provides some possible future work recommendations.

\section{Reservoir Operation Optimisation Innovation and Techniques}

Several methods for solving the non-linearity constrained optimisation problem have been successfully developed over the last few decades. The chronological order of reservoir operation optimisation innovation and techniques starts with the traditional models. Linear programming (LP), non-linear programming (NLP), dynamic programming, Lagrange relaxation [6], and network optimisation are all the reservoir models that had been applied widely in the past [7-10]. The further development of artificial intelligence since the turn of the twenty-first century led to refinements in some of the more popular models in order to achieve their finer precision. The evaluation algorithms include genetic algorithms (GA), genetic programming (GP), and differential evolution (DE). The time order for reservoir modelling is now turned to evolutionary algorithms in swarm intelligence (EAs-SI) such as the particle swarm optimisation (PSO). Following that, a hybrid or blend of either the EA or EA-SI, has been widely implemented in the optimisation of reservoir operation to solve the existing respective algorithms' premature convergence issues [11], shortcomings in complex optimisation problem like dimensionality [12], huge computation burden [13], and parameter tuning [14]. Hence, the variety of MHAs has been enormously introduced by the researchers to optimise the reservoir operation, specifically in the last decade. The MHAs were partitioned into following categories [15]: -

- evolutionary based (e.g., coral reefs optimisation)

- swarm-based (e.g., particle swarm optimisation)

- physics-based (e.g., simulated annealing)

- human-based (e.g., teaching-learning optimisation)
- bio-based (e.g., invasive weed optimisation)

- system-based (e.g., water cycle algorithm)

- math-based (e.g., Sine Cosine Algorithm)

- music-based (e.g., Harmony search)

- probabilistic based (e.g., cross-entropy method)

Due to the popularity in MHAs beginning in the past decade, a host of studies has been conducted using these approaches for the reservoir optimisation policy. However, it is not possible to compile all of them in this review for the sake of the discussion because doing so would require many more pages than this paper is afforded. Nonetheless, Table 1 and Fig. 1 show the reservoir models that will be discussed in this review. Table 2 presented some important abbreviations used in this review.

Figure 1 depicts the range of the reservoir models included in this review. Table 1 presents what's in the past decade (from year 2011 to 2021) are the comprehensive research works on the reservoir models which have been widely enacted for optimisation of the reservoir operations. Figure 2 shows the summary of Table 1, with data segregated into the years versus the number of papers contributed to this review. Table 1 summarises several pieces of information, including the classification of the reservoir model used, the formulation of the reservoir's problem, the evaluation methods, the benefits associated with the reservoir's optimisation objective, and finally, the reservoir system used in the case studies. The percentages of respective technical aspects found in Table 1 is illustrated in Fig. 3 in the form of pie charts.

Over the timeline, the reservoir model could be classified as traditional models (TS) and these included deterministic, or stochastic in dynamic programming, linear and non-linear programming; to the more current fare of models such as the evolutionary algorithm (EA) includes GA, GP, etc. or diversify into swarm intelligence (EA-SI) and the recent overwhelming meta-heuristic algorithms (MHAs).

The problem formulations for the reservoir operations consist of three parts: (1) objective functions (OF); (2) threshold or constraints (T); and (3) penalty functions (PF). An objective is a scalar variable that sums up system performance over time, according to the OF definition. The formulation problem in optimisation of reservoir operation aims either at minimising or maximising of the objective function for that particular project or benefits (e.g., irrigation, hydropower, ecology). Additionally, the threshold or constraints represent all the equations necessary to derive the objective from the decision variables. The Penalty functions (PF) are to convert the infeasible solution to a feasible solution. There are five categories of the PF: exterior [16], interior [17], static [18], dynamic [19] and adaptive [20].

There are a few metrics for the efficacy of algorithms to be verified and evaluated [21]. The terms reliability, resilience, 
Table 1 Research works on reservoir operation models used in past decade from year 2011 to 2021

\begin{tabular}{|c|c|c|c|c|c|c|c|c|c|c|c|c|c|c|c|}
\hline \multirow[t]{2}{*}{ Ref./Year } & \multicolumn{4}{|c|}{$\begin{array}{l}\text { Classification of reservoir } \\
\text { model }\end{array}$} & \multicolumn{3}{|c|}{ Problem formulation } & \multicolumn{2}{|c|}{ Evaluation } & \multicolumn{3}{|l|}{ Benefits } & \multicolumn{3}{|c|}{ Reservoir system } \\
\hline & $\mathrm{TS}$ & EA-SI & EA & MHA & $\mathrm{OF}$ & $\mathrm{T}$ & $\mathrm{PF}$ & MP & RSP & Irrigation & Hydropower & Ecology & Single & Parallel & Cascade \\
\hline [26] & & & & $\checkmark$ & $\checkmark$ & $\checkmark$ & $\checkmark$ & $\checkmark$ & & $\checkmark$ & & & & & $\checkmark$ \\
\hline [27] & & & & $\checkmark$ & $\checkmark$ & $\checkmark$ & $\checkmark$ & & $\checkmark$ & & $\checkmark$ & & & & $\checkmark$ \\
\hline [28] & & $\checkmark$ & $\checkmark$ & $\checkmark$ & $\checkmark$ & $\checkmark$ & $\checkmark$ & $\checkmark$ & $\checkmark$ & & $\checkmark$ & & & $\checkmark$ & \\
\hline [29] & $\checkmark$ & $\checkmark$ & & $\checkmark$ & $\checkmark$ & $\checkmark$ & & $\checkmark$ & & & $\checkmark$ & & & & $\checkmark$ \\
\hline [30] & & $\checkmark$ & & & $\checkmark$ & $\checkmark$ & & & $\checkmark$ & $\checkmark$ & & & & & $\checkmark$ \\
\hline [24] & & $\checkmark$ & $\checkmark$ & $\checkmark$ & $\checkmark$ & $\checkmark$ & $\checkmark$ & & $\checkmark$ & $\checkmark$ & & & $\checkmark$ & & \\
\hline [31] & & $\checkmark$ & $\checkmark$ & $\checkmark$ & $\checkmark$ & $\checkmark$ & & $\checkmark$ & & & $\checkmark$ & & & & $\checkmark$ \\
\hline [32] & & $\checkmark$ & $\checkmark$ & $\checkmark$ & $\checkmark$ & $\checkmark$ & & $\checkmark$ & & & $\checkmark$ & $\checkmark$ & & & $\checkmark$ \\
\hline [33] & & & $\checkmark$ & $\checkmark$ & $\checkmark$ & $\checkmark$ & & $\checkmark$ & & & $\checkmark$ & & $\checkmark$ & & $\checkmark$ \\
\hline [34] & & $\checkmark$ & & & $\checkmark$ & $\checkmark$ & $\checkmark$ & & $\checkmark$ & $\checkmark$ & $\checkmark$ & & & & $\checkmark$ \\
\hline [35] & $\checkmark$ & & & & $\checkmark$ & $\checkmark$ & & & $\checkmark$ & $\checkmark$ & $\checkmark$ & & & & $\checkmark$ \\
\hline [36] & & $\checkmark$ & $\checkmark$ & $\checkmark$ & $\checkmark$ & $\checkmark$ & & $\checkmark$ & $\checkmark$ & $\checkmark$ & $\checkmark$ & & $\checkmark$ & & $\checkmark$ \\
\hline \multirow[t]{2}{*}{ Ref./Year } & \multicolumn{4}{|c|}{$\begin{array}{l}\text { Classification of reservoir } \\
\text { model }\end{array}$} & \multicolumn{3}{|c|}{$\begin{array}{l}\text { Problem Formula- } \\
\text { tion }\end{array}$} & \multicolumn{2}{|c|}{ Evaluation } & \multicolumn{3}{|l|}{ Benefits } & \multicolumn{3}{|c|}{ Reservoir system } \\
\hline & $\mathrm{TS}$ & EA-SI & EA & MHA & $\mathrm{OF}$ & $\mathrm{T}$ & $\mathrm{PF}$ & MP & RSP & Irrigation & Hydropower & Ecology & Single & Parallel & Cascade \\
\hline [37] & & $\checkmark \mathrm{SVM}$ & & & $\checkmark$ & $\checkmark$ & & $\checkmark$ & $\checkmark$ & $\checkmark$ & & & $\checkmark$ & & \\
\hline [38] & & & $\checkmark$ & & $\checkmark$ & $\checkmark$ & & $\checkmark$ & $\checkmark$ & & $\checkmark$ & & $\checkmark$ & & \\
\hline [39] & & & $\checkmark$ & & $\checkmark$ & $\checkmark$ & & & $\checkmark$ & $\checkmark$ & $\checkmark$ & & & & $\checkmark$ \\
\hline [40] & & $\checkmark$ & $\checkmark$ & $\checkmark$ & $\checkmark$ & $\checkmark$ & & $\checkmark$ & & & $\checkmark$ & & & & $\checkmark$ \\
\hline [41] & $\checkmark$ & $\checkmark$ & $\checkmark$ & $\checkmark$ & $\checkmark$ & $\checkmark$ & & $\checkmark$ & & $\checkmark$ & $\checkmark$ & & & & $\checkmark$ \\
\hline [42] & $\checkmark$ & $\checkmark \mathrm{NN}$ & & & $\checkmark$ & $\checkmark$ & & & $\checkmark$ & & $\checkmark$ & & $\checkmark$ & & \\
\hline [7] & $\checkmark$ & & & & $\checkmark$ & $\checkmark$ & & $\checkmark$ & $\checkmark$ & $\checkmark$ & & & & $\checkmark$ & \\
\hline [43] & $\checkmark$ & & $\checkmark$ & $\checkmark$ & $\checkmark$ & $\checkmark$ & & $\checkmark$ & & $\checkmark$ & $\checkmark$ & & & & $\checkmark$ \\
\hline [44] & & & & $\checkmark$ & $\checkmark$ & $\checkmark$ & & & $\checkmark$ & $\checkmark$ & & $\checkmark$ & & & $\checkmark$ \\
\hline [45] & & $\checkmark$ & & & $\checkmark$ & $\checkmark$ & & & $\checkmark$ & $\checkmark$ & $\checkmark$ & $\checkmark$ & & & $\checkmark$ \\
\hline [46] & $\checkmark$ & $\checkmark$ & $\checkmark$ & $\checkmark$ & $\checkmark$ & $\checkmark$ & $\checkmark$ & $\checkmark$ & $\checkmark$ & $\checkmark$ & & & $\checkmark$ & & \\
\hline [47] & & $\checkmark$ & $\checkmark$ & $\checkmark$ & $\checkmark$ & $\checkmark$ & $\checkmark$ & $\checkmark$ & $\checkmark$ & $\checkmark$ & & & $\checkmark$ & & \\
\hline \multirow[t]{2}{*}{ Ref. /Year } & \multicolumn{4}{|c|}{$\begin{array}{l}\text { Classification of reservoir } \\
\text { model }\end{array}$} & \multicolumn{3}{|c|}{$\begin{array}{l}\text { Problem Formula- } \\
\text { tion }\end{array}$} & \multicolumn{2}{|c|}{ Evaluation } & \multicolumn{3}{|l|}{ Benefits } & \multicolumn{3}{|c|}{ Reservoir system } \\
\hline & $\mathrm{TS}$ & EA-SI & EA & MHA & $\mathrm{OF}$ & $\mathrm{T}$ & $\mathrm{PF}$ & MP & RSP & Irrigation & Hydropower & Ecology & Single & Parallel & Cascade \\
\hline [21] & & $\checkmark$ & & $\checkmark$ & $\checkmark$ & $\checkmark$ & $\checkmark$ & $\checkmark$ & $\checkmark$ & $\checkmark$ & & & $\checkmark$ & & \\
\hline [48] & & & $\checkmark$ & & $\checkmark$ & $\checkmark$ & & $\checkmark$ & & & $\checkmark$ & $\checkmark$ & & $\checkmark$ & \\
\hline [49] & & $\checkmark$ & & & $\checkmark$ & $\checkmark$ & & $\checkmark$ & & & $\checkmark$ & & & $\checkmark$ & \\
\hline [50] & & $\checkmark$ & & & $\checkmark$ & $\checkmark$ & $\checkmark$ & & $\checkmark$ & $\checkmark$ & & & $\checkmark$ & & \\
\hline [51] & $\checkmark$ & $\checkmark$ & $\checkmark$ & & $\checkmark$ & $\checkmark$ & $\checkmark$ & $\checkmark$ & $\checkmark$ & $\checkmark$ & $\checkmark$ & & & & $\checkmark$ \\
\hline [52] & & $\checkmark$ & $\checkmark$ & $\checkmark$ & $\checkmark$ & $\checkmark$ & & $\checkmark$ & $\checkmark$ & $\checkmark$ & & & $\checkmark$ & & $\checkmark$ \\
\hline [53] & $\checkmark$ & & $\checkmark$ & $\checkmark$ & $\checkmark$ & $\checkmark$ & $\checkmark$ & $\checkmark$ & $\checkmark$ & $\checkmark$ & $\checkmark$ & & & & $\checkmark$ \\
\hline [54] & & $\checkmark$ & & & $\checkmark$ & $\checkmark$ & $\checkmark$ & & $\checkmark$ & & $\checkmark$ & & $\checkmark$ & & \\
\hline [55] & & & $\checkmark$ & & $\checkmark$ & $\checkmark$ & & & $\checkmark$ & & $\checkmark$ & & & & $\checkmark$ \\
\hline [56] & & $\checkmark$ & & & $\checkmark$ & $\checkmark$ & & $\checkmark$ & & $\checkmark$ & & & $\checkmark$ & & \\
\hline [57] & & $\checkmark$ & & & $\checkmark$ & $\checkmark$ & & $\checkmark$ & & $\checkmark$ & $\checkmark$ & & $\checkmark$ & & \\
\hline [58] & & $\checkmark$ & $\checkmark$ & & $\checkmark$ & $\checkmark$ & & $\checkmark$ & $\checkmark$ & $\checkmark$ & & & & & $\checkmark$ \\
\hline
\end{tabular}


Table 1 (continued)

\begin{tabular}{|c|c|c|c|c|c|c|c|c|c|c|c|c|c|c|c|}
\hline \multirow[t]{2}{*}{ Ref./Year } & \multicolumn{4}{|c|}{$\begin{array}{l}\text { Classification of reservoir } \\
\text { model }\end{array}$} & \multicolumn{3}{|c|}{$\begin{array}{l}\text { Problem Formula- } \\
\text { tion }\end{array}$} & \multicolumn{2}{|c|}{ Evaluation } & \multicolumn{3}{|l|}{ Benefits } & \multicolumn{3}{|c|}{ Reservoir system } \\
\hline & $\mathrm{TS}$ & EA-SI & EA & MHA & $\mathrm{OF}$ & $\mathrm{T}$ & $\mathrm{PF}$ & MP & RSP & Irrigation & Hydropower & Ecology & Single & Parallel & Cascade \\
\hline [10] & $\checkmark$ & & & & $\checkmark$ & $\checkmark$ & & & $\checkmark$ & $\checkmark$ & $\checkmark$ & & & & $\checkmark$ \\
\hline [9] & $\checkmark$ & & & & $\checkmark$ & $\checkmark$ & & $\checkmark$ & & $\checkmark$ & & & & & $\checkmark$ \\
\hline [59] & & $\checkmark$ & $\checkmark$ & $\checkmark$ & $\checkmark$ & $\checkmark$ & $\checkmark$ & & $\checkmark$ & $\checkmark$ & & & $\checkmark$ & & \\
\hline [60] & & $\checkmark$ & $\checkmark$ & $\checkmark$ & $\checkmark$ & $\checkmark$ & $\checkmark$ & & $\checkmark$ & $\checkmark$ & & & $\checkmark$ & & \\
\hline [61] & $\checkmark \mathrm{SR}$ & & & & $\begin{array}{l}\text { Regression } \\
\text { equa- } \\
\text { tions }\end{array}$ & $\checkmark$ & & & $\checkmark$ & & & & $\checkmark$ & & \\
\hline [62] & $\sqrt{ } \mathrm{E}$ & $\checkmark \mathrm{SP}$ & & & $\checkmark$ & $\checkmark$ & & & $\checkmark$ & $\checkmark$ & & & & & $\checkmark$ \\
\hline [63] & & $\checkmark$ & & & $\checkmark$ & $\checkmark$ & & $\checkmark$ & $\checkmark$ & & $\checkmark$ & & & & $\checkmark$ \\
\hline [64] & & $\checkmark \mathrm{SCE}$ & & & $\checkmark$ & $\checkmark$ & & & $\checkmark$ & $\checkmark$ & $\checkmark$ & & $\checkmark$ & & \\
\hline [65] & $\checkmark \mathrm{CCP}$ & & & & $\checkmark$ & $\checkmark$ & & $\checkmark$ & & & & $\checkmark$ & & & $\checkmark$ \\
\hline \multirow[t]{2}{*}{ Ref./Year } & \multicolumn{4}{|c|}{$\begin{array}{l}\text { Classification of reservoir } \\
\text { model }\end{array}$} & \multicolumn{3}{|c|}{$\begin{array}{l}\text { Problem Formula- } \\
\text { tion }\end{array}$} & \multicolumn{2}{|c|}{ Evaluation } & \multicolumn{3}{|l|}{ Benefits } & \multicolumn{3}{|c|}{ Reservoir system } \\
\hline & $\mathrm{TS}$ & EA-SI & EA & MHA & OF & $\mathrm{T}$ & $\mathrm{PF}$ & MP & RSP & Irrigation & Hydropower & Ecology & Single & Parallel & Cascade \\
\hline [66] & $\checkmark \mathrm{E}$ & $\checkmark$ & $\checkmark$ & & $\checkmark$ & $\checkmark$ & $\checkmark$ & $\checkmark$ & & $\checkmark$ & & & $\checkmark$ & & \\
\hline [8] & $\checkmark$ & & & & $\checkmark$ & $\checkmark$ & & $\checkmark$ & $\checkmark$ & $\checkmark$ & & & $\checkmark$ & & \\
\hline [67] & & & $\checkmark$ & & $\checkmark$ & $\checkmark$ & & $\checkmark$ & & & $\checkmark$ & $\checkmark$ & $\checkmark$ & & \\
\hline [68] & & $\checkmark$ & $\checkmark$ & & $\checkmark$ & $\checkmark$ & $\checkmark$ & $\checkmark$ & & $\checkmark$ & & & $\checkmark$ & & \\
\hline [69] & & $\checkmark$ & & & $\checkmark$ & $\checkmark$ & & $\checkmark$ & & & $\checkmark$ & & & & $\checkmark$ \\
\hline [70] & & $\checkmark$ & $\checkmark$ & & $\checkmark$ & $\checkmark$ & & $\checkmark$ & & & $\checkmark$ & & & & $\checkmark$ \\
\hline [71] & & & $\checkmark$ & & $\checkmark$ & $\checkmark$ & & $\checkmark$ & & $\checkmark$ & & & $\checkmark$ & & \\
\hline
\end{tabular}

$*$ EEPANET *E EPANET; *SP Strength Pareto; *SR Stepwise regression (SPSS); * SCE Shuffle Complex Evolution; $* C C P$ Chance-constrained programming

*NN Neural network; *SVM Support vector machine

vulnerability, and sustainability index are frequently used to describe how reservoir system policies perform (RSP) [22]. The RSP indicates that the results obtained are facilitated in the evaluation of the OF. The reliability objectives ascertain the failure to supply the exact amount of water demanded, the resilience objectives measure the time required to recover from a failure event, the vulnerability objectives evaluate the severity of the failure's consequences [23], and the sustainability index is used to evaluate and compare water management policies [24]. Further elaboration of the sustainability index classified into a few groups can be found in [25]. The equations for the RSP are as below:

Reliability $[X]=\frac{\left[\text { Number of time period t such that } X_{t} \geq D_{t}\right]}{n}$
Vulnerability $[\mathrm{X}]=\frac{\left[\text { Sum of postive value } \mathrm{X}_{\mathrm{t} \geq \mathrm{D}_{\mathrm{t}}}\right]}{[\text { Number of times an unsatisfactory event occured }]}$

Sustainability $[\mathrm{X}]=$ Reliability X Resiliency X $(1-$ Vulnerability $)]^{\frac{1}{3}}$

in which $X_{t}$ number of data greater or equal than $D_{t}$ (Demand); $n$ total number of data.

The model performance (MP) of the respective algorithms can be examined through the convergence speed, and the statistical evaluation such as best, worst, mean, standard deviation, root mean square error (RMSE), etc. under examined of various mathematical benchmarks functions.

Resiliency $[\mathrm{X}]=\frac{[\text { Number of times a satisfactory value follows an unsatisfactory value }]}{[\text { Number }, \text { of times an unsatisfactory occured }]}$ 


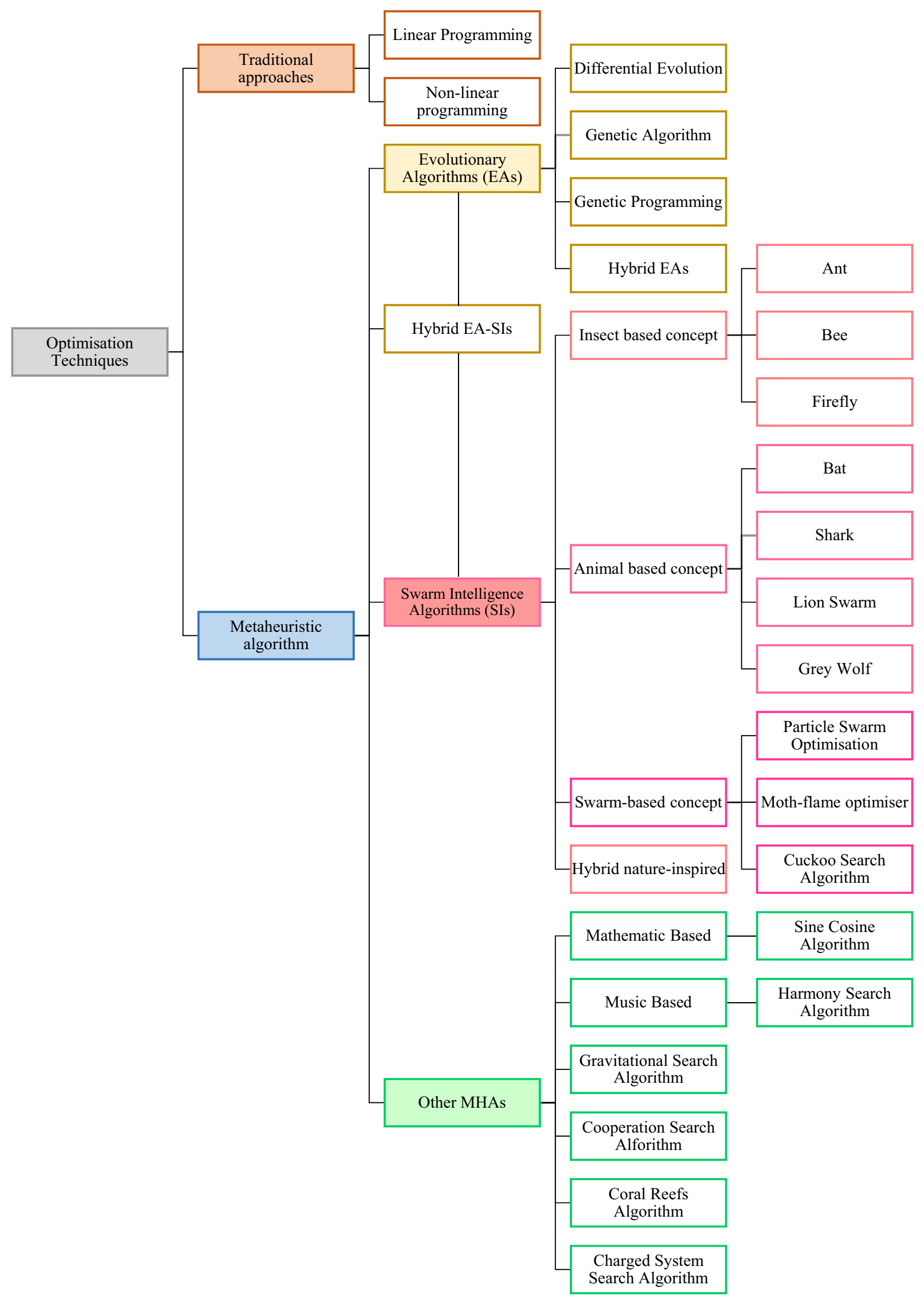

Fig. 1 Classification of the optimisation techniques reviewed 
Table 2 Abbreviations used in this review

\begin{tabular}{|c|c|c|c|c|c|}
\hline Abbrev & Description & Abbrev & Description & Abbrev & Description \\
\hline MO & Multi-Objectives & CCLP & Chance-Constrained Linear Programming & GWO & Grey Wolf Optimisation \\
\hline TS & Traditional Models & MILP & Mixed Integer Linear Programming & LSA & Lion Swarm Algorithm \\
\hline LP & Linear Programming & DDDP & Discrete Differential Dynamic Programming & MFO & Moth-Flame Optimisation \\
\hline NLP & Non-Linear Programming & SDDP & Stochastic Dual Dynamic Programming & IMFO & Improved MFO \\
\hline DP & Dynamic Programming & DC & Decomposition-Coordination & R-IMFO & R-Domination MFO \\
\hline EA & Evolutionary Algorithms & POA & Progressive Optimally Algorithm & $\mathrm{CS}$ & Cuckoo Search \\
\hline MHA & Meta-Heuristic Algorithms & MIGA & Interactive Multi-Tiered GA & ICGC & $\begin{array}{l}\text { Individual Constraints And } \\
\text { Group Constraints }\end{array}$ \\
\hline GA & Genetic Algorithms & NSGA-II & Non-Dominant Sorting GA II Algorithm & DAP & Dynamic Adaptive Probability \\
\hline GP & Genetic Programming & PMOGA & Parallel Multi-Objective GA & IMOCS & Multi-Objective Cuckoo Search \\
\hline $\mathrm{DE}$ & Differential Evolution & A-DEPSO & Adaptive PSO Algorithm & HB-SA & Bat-Swarm Algorithm \\
\hline PSO & Particle Swarm Optimisation & PC-PSO & Passive Congregation PSO & SCA & Sine Cosine Algorithm \\
\hline EA-SI & $\begin{array}{l}\text { Evolutionary Algorithms- } \\
\text { Swarm Intelligence }\end{array}$ & CIPSO & Constrained Version PSO & GSA & Gravitational Search Algorithm \\
\hline $\mathrm{OF}$ & Objective Functions & PCA & Principal Component Analysis & SCE & Shuffled Complex Evolution \\
\hline $\mathrm{T}$ & Constraints & $\mathrm{ABC}$ & Artificial Bee Colony & JA & Jaya Algorithm \\
\hline PF & Penalty Functions & SA & Shark Algorithm & $\mathrm{CRO}$ & Coral Reefs Algorithm \\
\hline RSP & Reservoir System Policies & NN & Neural Networks & CSS & Charged System Search \\
\hline MP & Model Performance & ANFIS & Adaptive Neuro Fuzzy Inference Systems & SLP & Stochastic Linear Programming \\
\hline RMSE & Root Mean Square Error & GWO & Grey Wolf Optimisation & IMFO & Improved Month Flame \\
\hline ISO & Implicit Stochastic Optimisation & LSA & Lion Swarm Algorithm & FS & Feature Selection \\
\hline ESO & Explicit Stochastic Optimisation & MFO & Moth-Flame Optimisation & & \\
\hline
\end{tabular}

Fig. 2 Chart summarising the number of papers in the year from Table 1

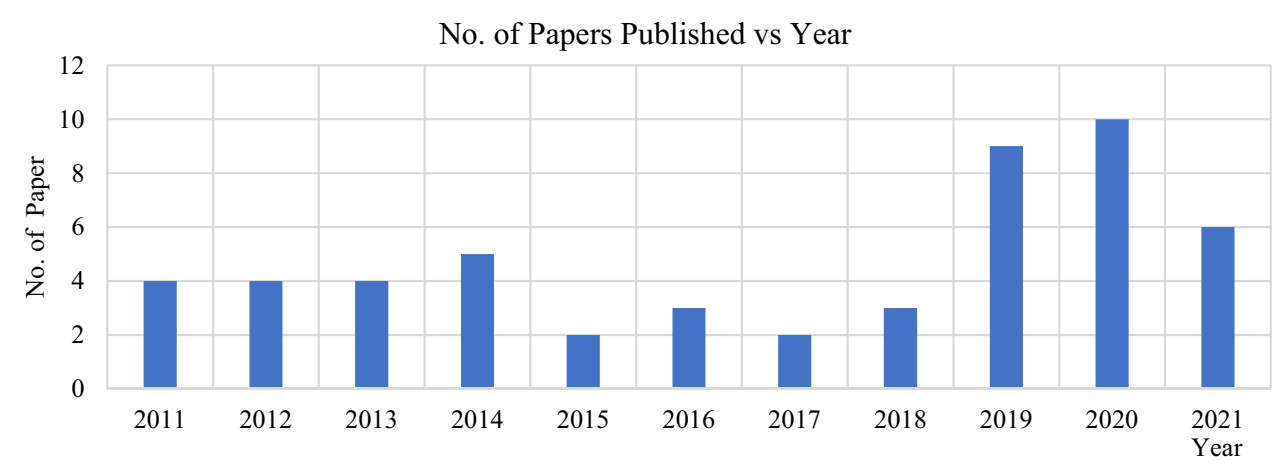

\subsection{Traditional Methods, Linear Programming (LP), Non-linear Programming (NLP) and Dynamic Programming in Optimisation of Reservoir Operation}

Traditional methods (TS) Using mathematical models to simulate and optimise reservoir operation can significantly improve their performance. Dams are traditionally designed for worst-case drought scenarios using Rippl's method, which creates the smallest reservoir capacity necessary to meet the target water demand [72-74]. One disadvantage of this approach is that it is difficult to apply to systems that are more complex than a single reservoir, such as the MO reservoirs [75]. As reported by [23], more adaptable approaches to these drawbacks have been proposed and discussed in [76-79]. In this method, the reservoir system is simulated against a long time series of reservoir inflows, iterating until the minimum reservoir capacity meeting the target objectives, is found. As a result, conventional optimisation techniques are broadly classified into two types: the Implicit Stochastic Optimisation (ISO) and the Explicit Stochastic Optimisation (ESO). The ISO uses historical observations and a statistical model to produce a diverse realisation [23]. The ISO, also known by its the more well-known name, the Monte Carlo optimisation [80], employs a deterministic optimisation model to determine optimal reservoir releases under a variety of inflow ensembles [80, 81]. Furthermore, the deterministic method is based on historical data, and 
Fig. 3 a Classification of reservoir model $\mathbf{b}$ Categories of Problem Formulation c Categories of Evaluation d Benefits $\mathbf{e}$ Categories of Reservoir system
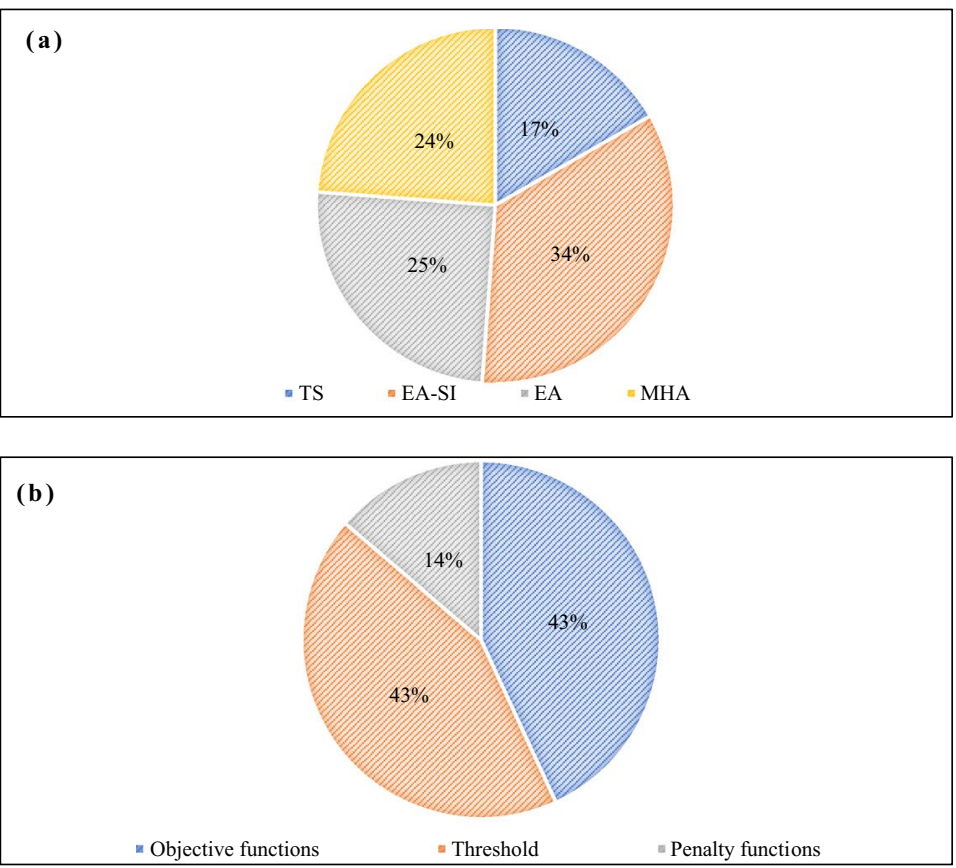

(c)

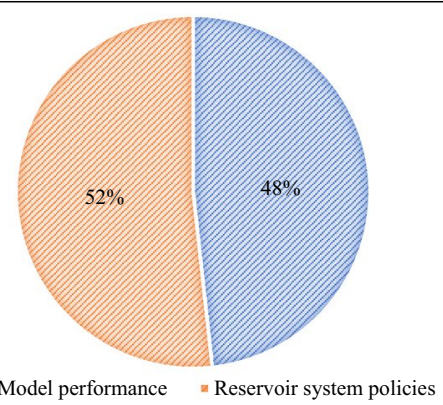

" Model performance $\quad$ "Reservoir system policies

(d)

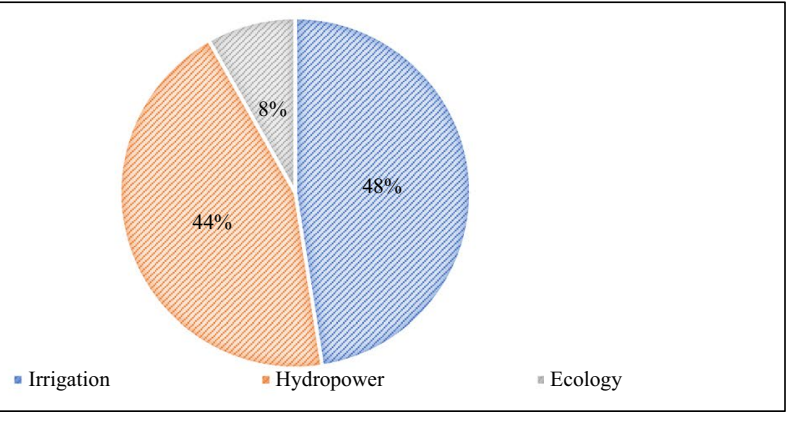

(e) 
it can be influenced by extreme conditions (like flood and drought). On the other hand, the ESO employs the statistical model directly during the optimisation process. The ESO approach is preferable in reservoir operation optimisation because it is more robust [83]. The ESO, on the other hand, is only appropriate for the most basic cases of a single input reservoir system, in which a detailed interpretation of inflow uncertainty via probability distributions is frequently possible. Additionally, it is necessary to consider the implications and magnitude of these trade-offs at spatial and temporal scales in order to facilitate transparency and comprehension [84]. Thus, linear programming is used to advance the innovation of model efficiency in reservoir optimisation.

Linear programming ( $L P$ : The LP was widely used for problem optimisation in the reservoir in both the standard and modified forms [85]. The Stochastic methods comply with LP (SLP), and chance-constrained LP (CCLP) are included. The SLP is known to have a single Markov chain because of inflows. Several studies have recorded SLP performance in reservoir systems. In order to represent a single operating strategy for the reservoir, [86] built a SLP. In the production of hydropower, Houck applied a linear decision law [85]. The CCLP was developed by several researchers to be used in various case studies [86, 87]. In the CCLP, the violation of a restriction was held within reasonable limits (may be specified as such percentages) when the release strategy was planned. Many reality challenges are non-linear, which implies that complications emerge while the fundamental priority is high. The mathematical calculations in the LP are also highly complicated and repetitive for high-dimensional subjects. In the case of optimising reservoir release, the problem is primarily nonlinearity, timedependent variables, and multi-target parameters. Under such instances, it is always impossible that the LP is used to simulate and last [89]. An improved study developed for respective optimal reservoir operations at the Laar Dam, the Latian Dam, and the Karaj Dam in Iran, was proposed by [90]. A mixed integer linear programming (MILP) model was also developed for operating the Tehran-Karaj reservoirs in a systematic manner. The MILP have several drawbacks such as impossibility of considering nonlinear affects; the necessity of considering all the time periods at once; the risk of high dimensionality of the problem which difficulties for optimising in reservoir operation. Nevertheless, these problems in MILP has been discussed and reviewed by [91] to tackle the problems faced in MILP.

Nonlinear programming (NLP) The equality and inequality constraints will overcome a nonlinear problem. The advantages and running costs as a non-linear formation are also the main functions. The use of NLP in these cases is very popular. Some studies in this field were carried out mainly for hydropower generation [92]. Different forms of the NLP were implemented with specific mathematical formulations to overcome the nonlinearity of the equation. The programming is independent, with the gradient projection method, the integrated gradient procedure [93], Lagrange procedures [94], etc., the NLP is not achieving worldwide optimum solutions because it is confined to optimum local structures of greater dimensionality [89]. The global optimum preference is a major problem in multipurpose reservoir operations optimisation, and the time needed for convergence is difficult for non-linear programming. Furthermore, a simulation built on integrating inexact chance constrained the NLP and probability distributions to deal with uncertainties was implemented to handle wastewaterenvironmental optimisation operations [65]. However, this approach lacks knowledge of reservoir policy.

Dynamic Programming (DP) The ability to handle nonlinear, non-continuous objective functions and constraints makes the DP and SDP models popular reservoir models [83]. However, to solve the "curse of dimensionality" in the DP and SDP, an improved DP with concave utility function has been employed in reservoir operation [8]. Furthermore, another improved DP method namely the Discrete differential dynamic programming (DDDP) has been utilised in optimisation of reservoir operation [95-97]. Due to the searching space being too huge, the DDDP will hardly obtain the optimal solution. In addition, the stochastic dual dynamic programming (SDDP) is an algorithm derived from the stochastic dynamic programming (SDP). In order to maximise the hydropower production at the case study for the Senegal River in Africa the SDDP was proposed by [35]. According to the results, the SDDP improved the single objective function for hydropower by $+9 \%$. However, this study revealed the negative aspect that when more reservoirs are built in the future, it will result in irregular electricity production. As a result, optimising reservoir operation is a complex trade-off needing very intense balancing. According to the authors, the study could imply the need for integrating with other reservoir functions based on future needs in order to provide at the best reservoir policies. On the contrary, the Decomposition-coordination (DC), also known as the "two-level" algorithm, has been widely implemented in optimisation of reservoir operation to overcome the shortcomings of the DDDP $[97,98]$. Each non-coupling subsystem is coordinated and optimised using this method. Decomposing and decoupling reduce the original system's complexity [10]. However, the DC's technique makes sense only if the method of coordination used is effective and the convergence of the coordination for this algorithm is particularly important and shall be focused on. Apart from the DC, the Progressive optimally algorithm (POA) divides multi-stage problems into subproblems and enhances the quality of the solution via a continuing approximation [30]. The dimensionality difficulties in the POA caused by the comprehensive combination of discrete state or decision variables. However, the integration 


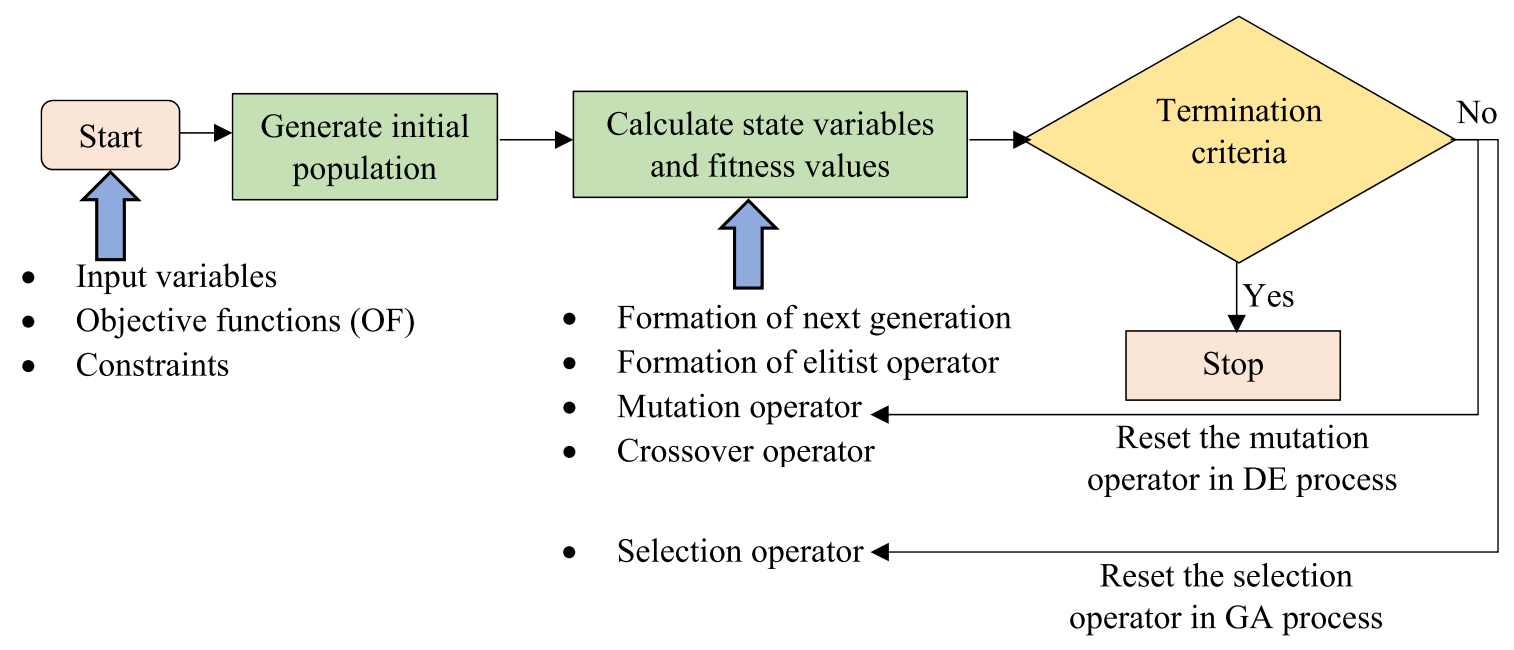

Fig. 4 Simple flow charts of the GA and DE

of the uniform design (UD) with the POA introduced by [100] is capable to solve the shortcomings of the POA. After that, the researchers investigated the heuristic optimisation which are problem-dependent techniques. The expansion of heuristic rules based on gene expression programming was described in [101]. It also consists of construction heuristic (e.g., greedy methods) via iteration and descending heuristic that only looks for the local optimum. Due to their characteristic of being too greedy and usually end up being trapped in a local optimum, thus failing in the search for global optimum solution. More advanced techniques involve other models in optimisation of reservoir operation are presented in Table 1 , namely the GA, GP, DE, etc. under category of EAs; whereas the PSO, etc. under the EAs-SI begun from year 2011; whilst nature-inspired algorithm under MHAs were initiated since 2014.

\subsection{Review of Evolutionary Algorithms (EA) for Optimising Reservoir Operations}

The development of the metaheuristics begin with the Evolutionary Algorithms (EAs), namely the Differential Evolution (DE) [102], Genetic Algorithm (GA), and Genetic Programming (GP). Different cultures have evolved and learned how to adapt the changes based on Darwin's evolution theory. The EA 's fundamental concept is to create a population of candidate solutions through a selective mechanism like natural selection, evolution, and reproduction before achieving better solutions [103]. Continuing the generation loop can aid in identifying, optimising, and designing problems. The GA introduced by [104] is one of those popular EA which was implemented in the optimisation of reservoir due to its simplicity and problemindependent application [37, 38]. A simple flowchart of the GA and DE is shown in Fig. 4. The execution of GA to optimise the Shihmen Reservoir for irrigation purposes was demonstrated in [71]. However, the authors found that the GA frequently struggles to decompose the largescale reservoir problems into smaller scale ones in order to speed up and improve the searching solutions. An interactive multi-tiered GA (MIGA) was proposed by the authors to investigate the optimal reservoir operation solution. A 20-year operation utilising the blended or hybrid model showed a $25 \%$ increase in fitness value and $80 \%$ reduction in computation time required by MIGA. Other than that, the non-dominant sorting GA II algorithm (NSGA-II), also known as a Pareto front, is another popular modified method of the GA implemented in the optimisation for the MO matter in reservoir operation [33]. The NSGA-II is described in more detail in [104, 105]. There was a little information on a dam releases to balance between the power generation and fish habitat protection (ecology) [44, 67]. For example, in Vento of Italy, Cioffi and Gallerano highlighted that was very few studies concerned the ecology in reservoir optimisation as a complex and large-scale optimisation to determine the release rule while maintaining the flow regime to the downstream in order not to affect the river habitat quality [67]. It was a very complicated process to balance the reservoir policy. The authors used the $\epsilon$-constraint methods and the NSGA-II to find the optimal Pareto front for this trade-off matter. Comparison of both approaches showed that the results of robustness in the $\epsilon$-constraint method was computationally faster and allowed for direct sensitivity analysis of the solution under constraint. However, in terms of the broader space solution, the NSGA-II results can be informative. Moreover, on the same benefits of trade-off in ecology, Feng et al. pointed out the alternative integration for the GA, which was a parallel multi-objective GA (PMOGA), conducted at the Wu Hydropower in China [48]. The PMOGA was 
created to improve the feasibility of solutions and the rate of convergence of the stand-alone in GA. Despite the fact that the PMOGA required more resources than the traditional GA, the results showed a significant improvement in terms of the standard deviation of power generation and water deficit by 69.23 and $27.44 \%$, respectively. Even so, because the model parameters and constraints are very complicated, the PMOGA was unable to make sure that the optimisation methods for hydropower operation applied to all possible conditions. The authors suggested that this design of work be carried out in other case studies or in real-reservoir optimisation by incorporating other heuristic approaches. The NSGA-II was also used to optimise the world's largest hydro/PV hybrid power station in Qinghai, China [55]. The authors demonstrated that hydropower was an ideal PV power compensation resource, especially during the rainy season, when solar radiation is reduced by rainfall and water resources are widely available. For the hydropower optimisation, the boundary condition was replaced by solar radiation and temperature data from the PV power, and the decision variable was reservoir release, in order to reduce power output variance and maximise annual power generation. The NGSA-II provided balanced results in terms of computational accuracy and cost by separating hydropower and PV power. The authors suggested that the design of this study be more focused on the coupling of the short-term and long-term, and by using other integrated methods as well. Beyond these popular GA blending approaches, the MOGA's originality led to an improvement in $\mathrm{MO}$ reservoir operations, namely the hybrid matched block bootstrap, which improved simulation-optimisation in streamflow and reservoir operation [68]. However, this method oversimplifies to apply in realworld scenarios, indicating it lacks reliability concepts and is sensitive to sample length. The RSP index's assessment can help to address this.

\subsection{Review of Hybrid Evolutionary Algorithms (EAs) for Optimising Reservoir Operations}

The hybrid algorithm has the advantage in overcoming the flaws of the stand-alone algorithm. The multi-level hybridisation [107], features a stochastic/deterministic alternate method that is executed alternately, whereby the outputs from the previous algorithm are then fed into the following hybridised algorithm for further optimisation processing, whereas a stochastic/deterministic embedded algorithm is performed in parallel and independently. Both methods can be implemented in any optimisation field. The consistency of hybrid algorithms may be useful in studies involving the MO trade-offs (flood control, hydroelectricity generation, and water distribution). For example, the review in [108] demonstrated the integration of data-driven techniques with optimisation modelling in streamflow forecasting. A combination of the accurate reservoir inflow forecasting (artificial neural networks) and efficient optimisation (Pareto multiobjective DE) can improve daily hydropower generation at the Vanderkloof Dam [54]. The studies of blending neuralnetwork and EAs approaches were conducted in reservoir operation optimisation to obtain the best reservoir policy [42]. The water distribution model (EPANET) was combined with EAs to demonstrate the trade-off of water quality, pumping cost, and tank sizing of water distribution system [62]. Also, MO optimisation reservoir operations like the DE [109] and the PSO [66] are popular hybrid EAs because they are easy to implement and perform well. In addition, the MO-EAs were also implemented in other than reservoir optimisation, such as a strategy used in the design of experiments [110], as well act as radiation detection system [111]. The inertia weight and low diversity were two drawbacks of the PSO. While the PSO can find local optimum solutions, the DE is extremely reliant on its control parameters, and incorrect parameter settings can lead to premature convergence. By addressing the weaknesses of the DE and PSO algorithms, an adaptive (A-DEPSO) algorithm was proposed to improve their basic structure [31]. A-DEPSO uses cuttingedge technology to improve the global and local search. The proposed solution is being tested in southwest Iran on a fourreservoir hydropower system. This method outperformed other stand-alone methods, by accounting for $57 \%$ of the reduction deviation in the hydropower plant. An algorithm for a multi-dam and reservoir systems has been developed by [51]. The proposed hybrid method integrates the GA and krill algorithms. Integration overcomes the current GA algorithms' main flaws of poor convergence and local optima. Large-scale reservoir activity discretisation provides a realtime solution sensitive to small parameter changes. Using both algorithms, the global optimisation models can quickly find the global optima. This paper investigated the proposed hybrid algorithm for single, multiple, and cascade dams and reservoirs. The authors compared the proposed hybrid algorithm in terms of RSP in order to verify and evaluate the efficiency of the algorithm. The proposed hybrid algorithm found the global optimal value for all the cases. However, accurate simulation is required for reservoir optimisation, which is a formula for controlling a dam or reservoir in the best possible way. In short, hybrid EAs addresses complex water resources management issues. The drawback of the stand-alone EAs is however complemented by another algorithm in terms of enhancement or improving the stand-alone algorithm. 


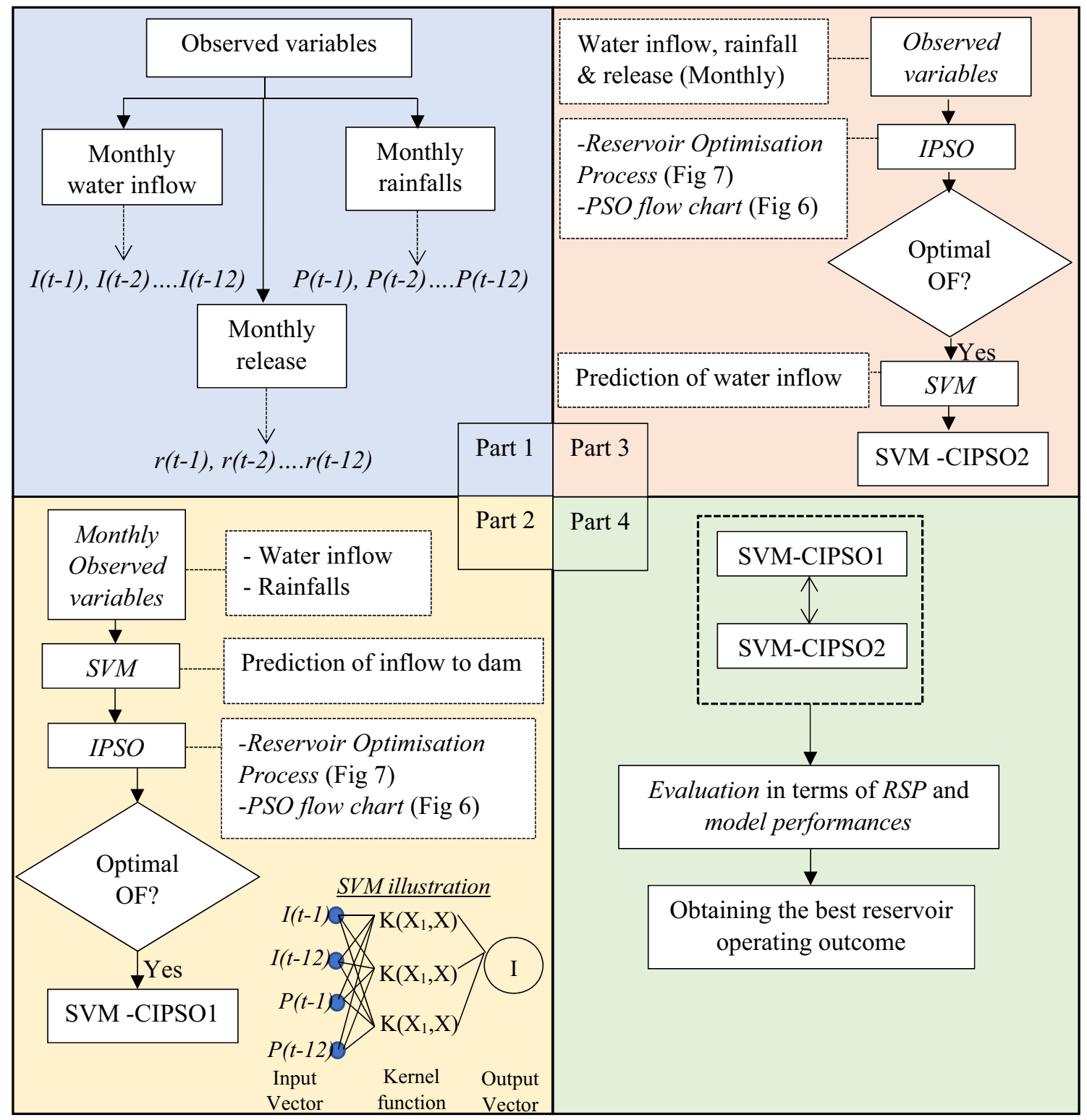

Fig. 5 Conceptual flow of the SVM-CIPSO1 and SVM-CIPSO2 hybrid reservoir models

\subsection{Review of Hybrid EA-Swarm Intelligence (EA-SI) for Optimising Reservoir Operations}

In one field, one algorithm could possibly be sufficient to solve the problems. However, when dealing with water resources, these objectives and benefits involved can be more complicated. Methodologies for various activities are distributed based on the approach that is best suited to the situation. Thus, the hybrid algorithm aids in the correction of the flaws in the stand-alone algorithms. As the configuration of the PSO is simple, this also led to the solutions obtained that converged prematurely and also consequently suffers loss of the population diversity. Thus, there are few studies in this review that focus on the blending approach of the PSO to solve the $\mathrm{MO}$ reservoir operation in order to gain the benefits of the policies. The passive congregation theory in particle movement (PC-PSO) was suggested in [50] to enhance the stand-alone PSO, which was tested in Malaysia's Klang Gates Dam. The PSO was a very good optimiser, however, in terms of RSP, the PC-PSO was 5\% more reliable, 0.02 less vulnerable, and 1.5 times more resilient than the stand-alone PSO. This is very important and crucial for the resilience index and the vulnerability index, during extreme weather event (heavy-rainfall or extreme draught). Another popular technique for improving the PSO (IPSO) was consolidating with the Support Vector Machine (SVM). The SVM showed how machine learning can simplify the complex processes and nonlinear problems. Figure 5 depicts the conceptual 
Fig. 6 Flow of the PSO model reservoir optimisation

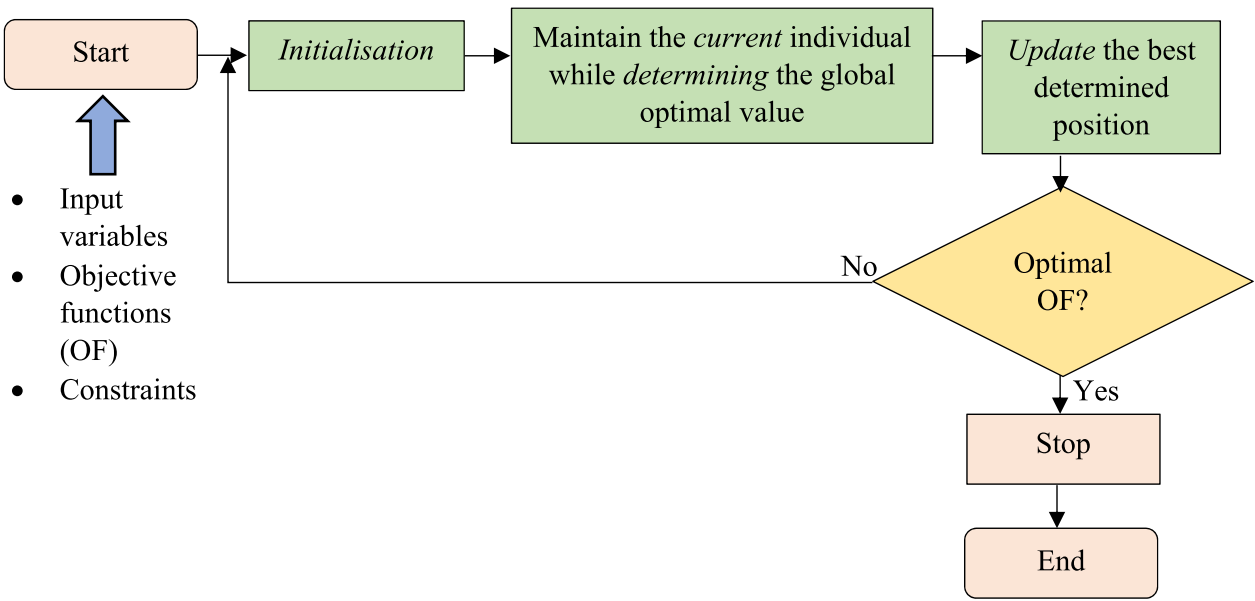

flow of these investigations as hybrid reservoir models. With uncertain inflows, Moeini and Babaei used the original IPSO concept and enhance it to a constrained version (CIPSO) [37]. The CIPSO constraint is explicitly satisfied, reducing the search space and computational cost. The authors proposed two scenarios: (a) SVM-CIPSO1:- uses the SVM to predict the water inflow into reservoir and then these predicted variables were implemented to solve the optimisation matter using CIPSO; (b) SVM-CIPSO2:-uses CIPSO to solve and optimise reservoir operation using historical data, then the optimised results were transmitted to the SVM in order to predict optimal water release policy for future conditions. The results showed that the second scenario, SVMCIPSO2, outperformed in the RSP criteria and increased the sustainability index by $11.27 \%$. With a constrict search space, certainly this method performed better. Secondly, the historical data was fed into CIPSO, and the optimised results were then transmitted into SVM in which SVM is a data-driven model that can mimic a previously optimised data pattern. As a result, the second scenario's modelling is more effective. Furthermore, Zhang et al. utilised the IPSO and the applied constraints to optimise the cascading reservoir systems in the Minjiang Basin for hydroelectric power scheduling [70]. The other popularity of its enhancement in the PSO was the multi-elite guide PSO (MGPSO) which has good global optimum capability. This method was then executed in a MO reservoir system for 10-cascaded hydro plants. The performance showed that the MGPSO provided with smaller energy deficit as compared with the DE and PSO [63]. The other integration of the PSO was with an estimation of distribution algorithm (EDA) to solve the MO reservoir operations. The ease of the EDA linkage between the decision variable, and thus the MO-PSO-EDA has a good capability in the trade off in the flood control operations at the Ankang Reservoir to other MO algorithms tested with six mathematical benchmarks [56]. Aside from that, there are a few studies that the SI is integrated with a statistical data analysis tool and biology immune system concept. For example, Yang et al. demonstrated a multi-objective complex evolution global optimisation method with the principal component analysis (PCA) and crowding distance operation (MOSPD) for the hydropower reservoir operation of the Oroville-Thermalito complex in California [57]. Another example is the immune algorithm-based PSO, which combines the concept of immune information processing mechanism with the PSO in order to attain good global optimum capability [69]. However, these conjunction methods were not the popular under the category of SI for optimising the reservoir operations.

To summarise the findings of previous studies, EAs were often used as a search behaviour that can be fitted to the problem at hand, as well as handle numerous objectives simultaneously. Its ease of interfacing with simulation models and handling constraints made it suitable for hybridisation.

\section{Review of Swarm Intelligence (SI) for Optimising Reservoir Operations}

Slowly but surely, the progression of the optimisation for the reservoir models has reached the point under the Swarm Intelligence, namely PSO, Artificial Bee Colony (ABC), the Nature-inspired categories etc. The simple flow chart for the PSO model in reservoir optimisation is shown in Fig. 6. PSO is well-known and is widely used in various engineering fields [112]. The trade-off between maximising hydropower and flood mitigation, with the PSO at the Mosul Dam and Badush Dam in Iraq was demonstrated by [34]. The first model was the PSO algorithm for a single reservoir system (PSOS), which was developed to validate the optimisation model. The second model was the PSO algorithm for a multi-reservoir system (PSOM), which was used to determine the best operation policies for the complex reservoir 
trade-off benefits. The PSOM showed efficiency in achieving optimal trade-offs under a variety of constraints and inflow types. Another popular enhancement technique is the chaotic PSO (CPSO), which is based on an improved logistic map and uses the discharge flow process as the decision variables in conjunction with the death PF. The suggestion of CPSO to reduce the standard deviation of the discharge flow process can be found in [58]. Simultaneously, to deal with the constraints for solving OF, a piecewise linear interpolation function (PLIF) was used. The results obtained then demonstrated that the CPSO was superior to the GA, DE, and PSO. However, the MO flood control operations should be considered for more efficient scheduling. Other than the trade-off of ecology in aspect of river habitat quality, the sediment issue is also a topic of concern in reservoir operations, with even fewer studies conducted for the balance benefits in reservoir policy. In order to maintain and provide a healthy Yellow River in China, Bai et al. established a tradeoff between water-sediment relationships [45]. The authors used the PSO and its enhancement (feasible search space) to optimise the MO (five objectives) water-sediment regulation for the purpose of reducing disasters and maximising the benefits of two cascade reservoirs' water conservancy facilities. Furthermore, the same concepts of execution in the parallel multi-objectives (PMO) were implemented not only in the GA but also in the PSO for cascade hydropower reservoir operations in southwest China [49]. After that, the time order continued to evolve into the nature-inspired algorithms. The nature-inspired algorithms are easily to handle, and majority of these algorithms consists of three phases whereby this situation is not easily trap in local optimum also looking for global optimum solutions. The following sub-section begins with Nature-inspired meta-heuristic algorithms to solve the optimisation problems in reservoir operation by mimicking biological or physical phenomena under category of SI.

\subsection{Review of Nature-Inspired Under Category of Sls for Optimising Reservoir Operations}

Typically, the nature-inspired MHAs undergo two distinct phases of search, namely the exploitation and exploration, in order to conduct complete space searches, as seen in Fig. 7. Figure 7 also depicts the general concept of the reservoir optimisation procedure involved for problem formulation, evaluation criteria, etc. The process of how to determine the appropriate reservoir models are further described in Sect. 4.1. The next paragraphs describe the studies on optimisation of reservoirs, utilising various MHAs, as previously summarised in Table 1 .

This paragraph focused on the insect-based algorithms (ABC, firefly, ant-colony). The most popular under category of SI in optimising the release policy for reservoir system are namely the $\mathrm{PSO}$ and the $\mathrm{ABC}$. They were demonstrated at the Aswan High Dam, AHD [59] and the Klang Gate Dam, KGD [60] whereby the ABC was under insect-based algorithm of the SI Ant-Colony algorithm was utilised in the water distribution system design problems, and it was validated in a few mathematical test functions [113]. However, this study did not present any real optimisation problem, for only the model performance of convergence rate was shown. The same goes to the firefly optimisation conducted only in mathematical test function for the efficacy of the algorithms [114].

This current paragraph focusses on the animal-based algorithms (Bat, Shark, Lion Swarm, Grey wolf) under the category of MHAs. The shark algorithm (SA) was demonstrated in operations where Ehteram et al. aimed to minimise the water deficit at a cascading reservoir [52]. The RSP and model performances of the shark algorithm were evaluated by comparing it to another stand-alone algorithm (GA and PSO). In terms of model performance, the SA outperformed the other two stand-alone algorithms. Even amongst the RSP evaluation, the SA still has the highest reliability (96\%), and the lowest vulnerability (31\%). Because the SA is a stochastic search system, the authors proposed integrating it with data-driven techniques like neural networks $(\mathrm{NN})$ or adaptive neuro fuzzy inference systems (ANFIS) to act as a reservoir simulation model to mimic the behaviour of the release decision in reservoir systems. The concept of integration with a data-driven technique, that is ANFIS with the Grey Wolf Optimisation (GWO) was proposed for hydropower generation at the Dez basin [115]. The model performance showed the GWO-ANFIS was capable to forecast and optimise the hydropower generation and successfully contribute to policymaker. Few information relates to the Lion swarm algorithm (LSA) utilised in reservoir optimisation field. Liu et al. demonstrated the LSA in cascade hydropower, tested in various mathematical test and the model performance conducted in quantitative, convergence, statistical, and robustness analysis [116].

The focus in this paragraph is the swarm-based algorithms (Moth-flame Optimiser, Cuckoo Search) under the category of MHAs. Mirjalili invented the Moth-flame Optimisation (MFO) [117]. The MFO has several widely used enhancement methods. Three aspects of the MFO need to be improved to avoid a local optimum: update formula, inspiration of moth linear flight path, and flame population update strategy. This method is called improved MFO (IMFO). A new IMFO based on the R-domination (R-IMFO) was proposed in [32] due to the shortcomings of conventional Pareto domination. The R-IMFO improvement technique has successfully solved the cascade reservoir operation in conjunction with ecology and navigation. This followed by the most common enhancement techniques that is the Cuckoo Search (CS). Several methods exist for improving 
Fig. 7 General concept of reservoir optimisation operation and the flow of reservoir models with MHA

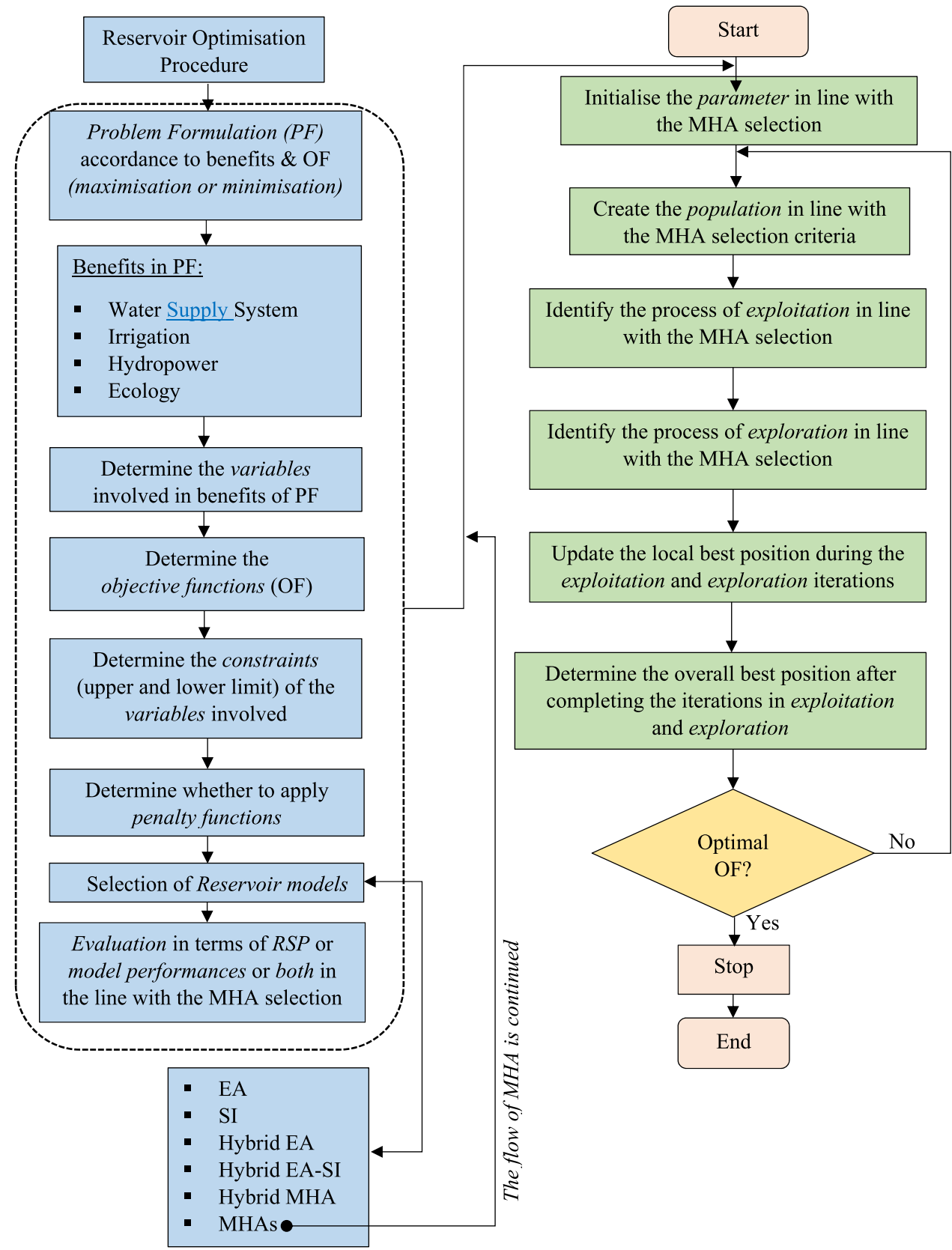

population initialisation. Individual constraints and group constraints (ICGC) and dynamic adaptive probability (DAP) are used to improve search efficiency and solution quality by avoiding local optima. In order to address one of MOCS's flaws, an improved multi-objective cuckoo search (IMOCS) was proposed by [118]. The results of combining the ICGC, DAP, and FSS techniques with the CS in MO hydropower reservoir operations were compared. However, ICGC may perform better over short-term hydropower station operations because water levels vary widely monthly, limiting ICGC's role.

\subsection{Review of Hybrid Nature-Inspired MHAs for Optimising Reservoir Operations}

The suggestion of the data-driven technique conducted by [46] revealed two artificial intelligence (AI) models, namely the support vector regression (SVR) and radial-basis function (RBF) for forecasting of the reservoir inflow and evaporation (Scenario 1); then the flow continued with the optimisation technique by integrating of machine learning technique in SA (SMLA), and the other stand-alone algorithm GA and PSO has been employed for the comparison in operation policies of the Timah Tasoh Dam located at 
the northern part of the country, specifically in the state of Perlis, Malaysia (Scenario 2).

The Scenario 2 followed the same procedure as Scenario 1 , but the observed deterministic variables of reservoir inflow and evaporation were used. In terms of optimisation, the results showed that the SMLA outperformed the other two algorithms (GA and PSO), while the SVR outperformed the RBF for the forecasted hydrological parameter data. In Scenario 2 , however, forecasted deterministic variables were used to optimise present unrealistic conditions in providing the best reservoir policy to minimise the water deficit. Aside from that, an ensembled technique called the Master-slave model approach, which is made up of PSO, DE, Whale Optimisation algorithm, and Crow Search algorithm [21] was followed. This approach gathered the domain information processed by each population in the respective algorithms, exchanged and evaluated the data based on the algorithms, determined the global optimum solution, and finally formed the Master-slave approach for generating the optimal reservoir policy at AHD. The combination of various MHAs is also known as the Reliability-Based Design Optimisation Problems, details of which can be found in [118]. The advantage of this approach is that it has a high ability to detect and perceive the reservoir system's significant stochastic nature and nonlinearity. However, future climatic and hydrological conditions at dam scales should be tested to see if the current reservoir policy can remain viable. Another widely hybridisation algorithm used in reservoir operation, namely the bat-swarm algorithm (HB-SA) was proposed by [47] to minimise the irrigation deficits at the Golestan Dam and Voshmgir Dam. The hybridisation accelerated the convergence rate, resulting in a usable real-time optimal solution for dam and reservoir. The proposed algorithm was then tested and validated against other algorithms [GA, PSO, and water cycle algorithm (WCA)]. HB-SA outperformed the other algorithms, with the highest reliability of 94\% and 96\% for the Golestan Dam and Voshmgir Dam, respectively. However, the same suggestion made in [21] has also been mentioned in this study, namely that future studies should take into account the lack of suitable climate conditions and the effect of climate change on reservoir operations.

\section{Other MHAs}

The Sine Cosine Algorithm (SCA) is a new swarm-based meta-heuristic method for global optimisation. An improved SCA was suggested by [40] for a sustainable growth and resource production strategy. To balance global exploration and local exploitation, a modified SCA was used. The agent evolution equation now includes random weighting agents generated by multiple leader solutions. Adaptive mutation was designed to increase swarm diversity. This method was then tested in a cascade hydropower reservoir in China. The SCA outperformed other algorithms in terms of convergence rate. The gravitational search algorithm (GSA) was proposed by [119]. The GSA has been used in the reservoir operation optimisation algorithm [29,53]. The approach employs gravity and mass interactions. The GSA was conducted at Iran's "Dez" reservoir to address the reservoir's simple and hydropower issues [120]. Unlike the GA, this algorithm tries to solve the large-scale optimisation problem by shrinking the search space. As a result, the algorithm was less sensitive to the initial guess generated randomly. The GSA is slow in the final phase of search but fast in exploration and exploitation, so hybridising GSA and PSO (HGSPSO) could improve both systems' shortcomings [121]. The HGSPSO can be suggested to be implemented in reservoir optimisation. Besides that, the harmony search [122] and the cooperation search algorithms [123] have also been widely been utilised for the MO engineering optimisation problem. However, as of now, both algorithms have been little used in very few research works in optimisation of reservoir operation. Also, the Shuffled Complex Evolution (SCE) is a fast and reliable parameter space search used in reservoir models. These results showed that the SCE was flexible and robust in meeting all of the objectives under all three scenarios (water supply only, hydropower generation only, and both) by taking into account the ecology of river habitat in the Xinfengjiang Reservoir in Southern China [64]. The advantage of the Jaya algorithm (JA) feature is that it is an algorithmspecific parameter, which means it does not require a lot of effort in parameter tuning, only needs of the population size and generations, and can still perform the same function as other MHAs in exploration and exploitation. Paliwal et al. demonstrated the role of JA in the optimal use and restoration of reservoir systems at the Muda reservoir [36]. JA was successfully applied in the aforementioned case study, and the results revealed that JA outperformed other algorithms in terms of faster convergence. A further comprehensive review of JA is given in [124]. Also, the Coral Reefs Algorithm (CRO) is the MHA under EA's category based on the idea of coral reef formation and reproduction. This algorithm was proposed by Salcedo-Sanz et al. (2014). Surface water reservoirs must be managed more efficiently than ever before due to climatic uncertainties, which may result in increased water demand and prolonged drought if reservoir policy is not adequately publicised and planned for. The CRO and its enhancement techniques were tested in cascading reservoirs using constrained (CCRO) to narrow the search space and reinforcement learning (CCRO-QL) based on machine learning [26]. Despite the fact that the results showed that the enhancement technique was highly successful in producing optimal reservoir policy, it is also known that the CRO is a new MHA in this field. Additionally, the algorithm that 
has gained recent popularity in system-based optimisation namely, the Charged System Search (CSS), was discovered in reservoir optimisation studies [24] and demonstrated using mathematical test functions [41]. A descriptive explanation of the CSS can be found in [126]. The CSS was compared to the other EA and EA-SI algorithms for reservoir optimisation at Klang Dam and was found to perform $96 \%$ overall reliability compared to the other algorithms [24]. The authors suggest that to get more promising results, other new reservoir models which have not been implemented yet ought to be looked into. Also, because this study covered the period 1987-2007 [24], the current reservoir policy should be investigated more closely if it were to continue to be used in future climate change scenarios. Further on from that, a study was conducted to investigate the optimal operation of cascaded hydropower plants using metaheuristic algorithms [127]. The two operation strategies plans mentioned in this study were the local optimization and global optimization. Local optimization allows for the upstream hydropower plants to achieve higher power energy than te global optimization. In contrast, the global optimization plan was more beneficial to the overall system in terms of reaching higher energy levels than the local optimization plan. The work was expanded to look into the best solutions for maximising the power energy of hydroelectric plants in cascaded systems [128]. In terms of operation strategies, the improved Cuckoo Search (ICSA) was then compared to the other PSO, Cuckoo Search Algorithm (CSA), Salp Swarm Algorithm (SSA), sunflower optimization algorithm (SFO), equilibrium optimizer (EO), and marine predator algorithm (MPA). The results showed that the ICSA outperformed in terms of higher configuration speed. The ICSA, on the other hand, required more parameter tuning to achieve high efficiency [128]. A recent thorough review on reservoir optimisation by utilising metaheuristic algorithms was given by [129].

\subsection{Comparison and Choice of Optimisation Reservoir Models}

The optimisation of the reservoir model enables the stakeholder and decision maker of the management for reservoir to figure out the approach that is more realistically with the adjustment of the parameter boundaries. The researchers have been making considerable improvements over the past decades to provide for more successful optimal operating policies. Based on the past reviews, a few assumptions for the reservoir optimisation operation can be summarised and mentioned herein. An optimal solution to the optimisation problem if provided through a properly implemented mathematical programming algorithm, only then that the objective value obtained, provides an approximately optimal solutions. Simulation modelling, on the other hand, does not guarantee optimality throughout the iteration process. It's crucial because optimal solutions are frequently linked to problem formulations, and if the problem formulation is misidentified or assumptions are made incorrectly, the results will be fall into the category of either under or oversimplified in that situation. As a result, this is an important factor to consider when selecting reservoir models for optimisation. Besides, the further reviews for these reservoir models' constructive analyses were mentioned and discussed in [23, 126, 127].

Nevertheless, a variety of reservoir models that were focused on the optimum reservoir operating policy, in order to obtain the maximum benefits of the reservoir system/best trade-off in reservoir policy, can be summarised from the above-mentioned research works conducted over the last decades. Another popular topic that has only recently been discussed is the incorporation of the hedging policy into hydropower reservoir systems through the use of MHAs $[25,26]$. Concurrently, simulation or modelling (NN, SVM, ANFIS, etc.) were used for forecasting the hydrological variables, followed by an optimisation process in the reservoir system, in which the whole process is known as the model simulation or modelling optimisation concept, or known as sim-heuristic. However, this practice commonly entailed in investigating of climate change events for future reservoir management purposes. There are several factors to consider when selecting reservoir models for optimisation in reservoir operation. The following are the criteria: -

- Objective function (Single, Bi, many or multi)

For example, simple tuning parameters should be sufficient if the case study involved single or bi-objective functions. This is due to the convergence rate and time saving priority. However, other complex reservoir models can be selected for comparison purposes.

- Constraints - Penalty functions

This will be determined by the complexity of the reservoir system under consideration. In reservoir systems, for example, the trade-off of irrigation and hydropower is the most common; however, if ecology or navigation are involved, this would certainly entail more constraints, or as in some occasions, needs the penalty function to be applied simultaneously with the constraints in order to convert the PF from an infeasible region to a feasible region and solve the MO. As a result, as the reservoir system becomes more complex, the reservoir models must be able to choose between local and global search algorithms. By doing so, only to manage in providing the best release operating policy.

- Feature selections (FS) methods

The various feature selection methods have been widely used in applications such as numeric and biomedical datasets. A thorough review on this topic is found in [132]. The authors had provided in detail, the 
Table 3 Overview of Algorithms discussed in above-mentioned research works

\begin{tabular}{|c|c|c|c|c|c|}
\hline Group & Name & Year & Type & Large Scale & Level of Difficulty \\
\hline \multirow[t]{5}{*}{ Evolutionary } & Differential Evolution & 1997 & Weak & No & Easy \\
\hline & Genetic Programming & 1964 & Weak & No & Easy \\
\hline & Bee-inspired & 2007 & Strong & No & Easy \\
\hline & Firefly-Based & 2010 & Strong & No & Medium \\
\hline & Bat-algorithm & 2010 & Weak & No & Easy \\
\hline \multirow[t]{4}{*}{ Swarm Intelligence } & Shark algorithm & 2016 & Best & Yes & Easy \\
\hline & Lion optimiser algorithm & 2015 & Strong & Yes & Medium \\
\hline & Grey Wolf Optimiser & 2014 & Best & Yes & Easy \\
\hline & PSO & 1995 & Weak & Yes & Hard \\
\hline \multirow[t]{2}{*}{ Swarm Intelligence } & Moth-flame algorithm & 2015 & Strong & No & Easy \\
\hline & Cuckoo Search Algorithm & 2009 & Weak & Yes & Medium \\
\hline Group & Name & Year & Type & Large Scale & Level of Difficulty \\
\hline \multirow[t]{10}{*}{ Other MHAs } & Sine Cosine Algorithm & 2016 & Strong & No & Easy \\
\hline & Harmony Search algorithm & 2001 & Weak & No & Easy \\
\hline & Gravitational search algorithm & 2009 & Weak & No & Easy \\
\hline & Cooperation Search algorithm & 2020 & Strong & Yes & Medium \\
\hline & Coral reefs algorithm & 2014 & Strong & No & Medium \\
\hline & Charged System Search & 2010 & Strong & No & Medium \\
\hline & Jaya Algorithm & 2016 & Good & No & Easy \\
\hline & Salp Swarm Optimization & 2017 & Good & No & Easy \\
\hline & Equilibrium Optimization & 2019 & Good & No & Easy \\
\hline & Archimedes Optimization & 2021 & Good & Yes & Easy \\
\hline
\end{tabular}

feature selection classification, and techniques. There are two main FS approaches: that is the search space and the strategy-based techniques. The most frequent search space implementations in reservoir optimisation are heuristic and meta-heuristic. The exhaustive random strategy under the search space category is insufficient for large dataset analysis because all possible solutions are easily explored. Both the filter and wrapper methods are strategy-based. However, these strategies are only suitable for correlation used in data mining. Apart from that, the studies related in objective, merit, and demerit based on feature selection of the SI was summarised in [101]. The following sub-section (a) shows some examples of MHAs and recommended on how to select the reservoir models based on the difficulties level, (b) the merit and demerits of all the algorithms discussed in for this overall review, as well as (c) the comparison of reservoir models between simulation and optimisation.

\section{2 (a) Overall Algorithms Based on The Difficulties and Suitability of data scale}

The overall algorithms discussed in this review is tabulated in Table 3 by addressing the suitability of the data scale used in these algorithms. The type of each algorithm defined the modal's workability in terms of unimodal, multi-modal, some hybrid and some composite functions. The definition of unimodal and multi-modal was briefly explained in [133]. For the concept, in a weak type, it was established that the workability of algorithms was capable of working fine only with unimodal and some multi-modal functions, while for the strong in type, it was defined as that algorithm working well with unimodal, multi-modal, some hybrid and some composite functions.

\section{3 (b) Merits and Demerits of the overview algorithms in above-mentioned research works}

In this section, a summary of the merits and demerits of each representative algorithm, as shown in Table 4 , is presented to support the decisions made in selecting the reservoir models mentioned above. Most reservoir models necessitate numerous iterations and perform poorly if the parameters are not properly tuned. Metaheuristics are designed to find near-optimal solutions because they are incapable of providing optimal solutions. Metaheuristics, on the other hand, have some advantages that can be used alone or in conjunction with other traditional techniques. As previously stated, researchers used a variety of significant evaluation methods to evaluate the efficacy, robustness, and performance of 
Table 4 Merits and demerits of the overview algorithms in above-mentioned research works

\begin{tabular}{|c|c|c|}
\hline Algorithm & Advantages & Disadvantages \\
\hline GA & $\begin{array}{l}\text { It is simple to implement. It can handle wide range of } \\
\text { objectives and constraints in nonlinear or discon- } \\
\text { tinuous. It can be used on its own to solve a given } \\
\text { problem. It is not reliant on any other algorithm or } \\
\text { heuristic }\end{array}$ & $\begin{array}{l}\text { It has no guarantee in global maxima be identified. It } \\
\text { easily trapped in local maxima. Losing population } \\
\text { density, thus premature convergence seldom occurs. } \\
\text { It lacks standard termination criteria. It can be time } \\
\text { consuming due to the large number of variables } \\
\text { involved }\end{array}$ \\
\hline DE & $\begin{array}{l}\text { It can converge to the global minimum } \\
\text { It is good at exploration and diversification. It has } \\
\text { ability deal with unimodal, and multimodal }\end{array}$ & $\begin{array}{l}\text { It has unstable convergence rate } \\
\text { It quickly falls into the local optimum }\end{array}$ \\
\hline PSO & $\begin{array}{l}\text { It is simple calculation. Because of its quick response, } \\
\text { it is ideal for dynamic applications }\end{array}$ & $\begin{array}{l}\text { Losing population density, thus premature convergence } \\
\text { seldom occurs }\end{array}$ \\
\hline $\mathrm{ABC}$ & It is flexible and few parameters tuning & $\begin{array}{l}\text { Less parameters tuning required, causes the accuracy is } \\
\text { diminished }\end{array}$ \\
\hline Ant-colony & $\begin{array}{l}\text { It is inherently parallel, as the solutions can be inde- } \\
\text { pendent and simultaneously } \\
\text { It avoids early premature convergence }\end{array}$ & $\begin{array}{l}\text { It guarantees the convergence aspect, however, the time } \\
\text { is undefined }\end{array}$ \\
\hline Algorithm & Advantages & Disadvantages \\
\hline Jaya Algorithm & $\begin{array}{l}\text { Straightforward configuration } \\
\text { No initialisation required }\end{array}$ & $\begin{array}{l}\text { Insufficient population diversity } \\
\text { Poor quality of final solution }\end{array}$ \\
\hline Equilibrium Optimization & High exploitation ability & $\begin{array}{l}\text { Hardly to work out the problem of scattering Difficul- } \\
\text { ties to define initial parameters }\end{array}$ \\
\hline Salp Swarm Optimization & Simple updating functions & Easily trapped in local opitimum \\
\hline Firefly \& Moth flame & $\begin{array}{l}\text { It has good diversification as it automatically divides } \\
\text { the population into different groups }\end{array}$ & $\begin{array}{l}\text { It is unsuitable for dealing with complex MO because } \\
\text { it can become trapped in local optima }\end{array}$ \\
\hline Bat, Shark, Lion, and grey wolf & $\begin{array}{l}\text { It aids in the balance of exploration and exploitation } \\
\text { during the search } \\
\text { It lacks fixed parameters, allowing for a quick } \\
\text { response from the exploration to the exploitation } \\
\text { stages } \\
\text { It is easy to implement and adaptable }\end{array}$ & $\begin{array}{l}\text { It unable to handle discrete problem. Hence, enhance- } \\
\text { ment technique or integration with other data-driven } \\
\text { technique or hybridisation with other MHA helps to } \\
\text { overcome this matter }\end{array}$ \\
\hline
\end{tabular}

the merit in each reservoir model. Model performance, for example, includes convergence rate and run-time, which are used to evaluate the performance of stand-alone algorithms. Second, each algorithm's robustness in solving high-dimensional complex matter. In addition, RSP is being evaluated in order to achieve and maintain a consistent success ratio among competing algorithms.

\section{4 (c) Comparison of Reservoir Models Between Modelling or Simulation and Optimisation}

For reservoir operation systems or real-time operation, various methodologies and algorithms can be used. Soft computing techniques, for example, can be used to predict rainfall in time series [134]. In reservoir operation systems over the last few decades, the most used in modelling or simulation are the ANN and GP, both of which are also known as regression or supervised machine learning approaches that were easily parameterised. ANNs typically do not provide a detailed description of the process by which they obtain a solution. Unlike GP, it generates computerised programmes that are used to predict models without assuming the form of the existing relationship. A study was conducted in Madhya Pradesh, India, in which the authors demonstrated two algorithms (GA and linear programming approach, LP) that could be implemented in real time at the existing Chiller reservoir system [135]. Both algorithms are capable of supporting the irrigation system in the area of study. The authors also claimed that these algorithms provided the best allocation of available water across the various crops in the fields. The GA outperformed the LP, but it would be difficult to apply it to more complex problems. As a result, for a better approach, reservoir optimisation operation approaches would be more focused in recent years in order to achieve the maximum benefits while incurring the least amount of loss in the reservoir operation system. These can be accomplished by utilising nature-inspired metaheuristic algorithms, as these algorithms possess both exploitation and exploration capabilities, which are not found concurrently in modelling and simulation. Simulation or modelling can be performed 
at first for the training and testing process or prediction purpose, followed by the integration of the optimisation technique, which will ensure a more precise result. With these details and a general overview, the author believes that the reader now has a quick start guideline for setting up the reservoir optimisation operation system.

\section{Conclusions}

Optimisation models are widely and judiciously used to support decision-making. In a lot of cases, the problems to be tackled are complex, non-linear, barely established and most likely sold in the form of an all-ready extremely large variety of remedies concept. This makes it virtually impossible to identify a variety of options that provide a wide range of trade-offs between competing goals, such as reducing costs and maximising environmental outcomes. Another aspect is the manipulating and implicit "optimising" methods, as part of which the optimum outcome was found to be surrounded with the aid of domain knowledge, practice, and intuition. Further examples include combining results from one or more simulation models such as from the very beginning of conventional approaches (linear and non-linear programming) to metaheuristic (evolutionary algorithms and swarm intelligence). Lastly, the hybrid approaches offer the way by overcoming the drawbacks of each algorithm and suitability of the variables into the models proposed to solve the optimisation objective functions of the reservoirs. Methods of metaheuristic algorithms, such as the Evolutionary Algorithm (EA), Swarm Intelligence (SI) founded on animal and insect behaviour-based concepts and swarm-based are some of the newer examples for ideal workable optimisation methods. This review summarised a discussion of various reservoir models developed for the purposes of optimising reservoir operations.

However, it can be concluded that the future recommendations of this review should be more focused and concerned with investigating the hydrological variables with climate change impacts on future reservoir operations under different climate scenarios, in accordance with global climate change strategies. As highlighted in the past studies [21, 47], the uncertainties of climate-change or scenarios may greatly influence the reservoir operation in future reservoir policy. Hence, this would allow for more practical and reliable for obtaining optimal reservoir operation rules into the future. Furthermore, reservoir models that were not mentioned in this review could be used in the field of real-world engineering. Examples, are the physics-based: Tug War Optimisation Algorithm (TWO) [136]; the human-based: coronavirus hearing immunity optimiser (CHIO) [137]; Ray Optimisation (RO) Algorithm [138]; and the hybridisation techniques in the learning-based intelligent optimisation [139].
In addition, the studies found in $[140,141]$ emphasised the importance of having future climatic variables which available in a specific region (case study) in order to determine the appropriate downscaling approaches, also part of the investigation for future direction of future reservoir optimisation operations considering the ever changing regional and global climate conditions.

Acknowledgements This study was funded by Universiti Tunku Abdul Rahman (UTAR), Malaysia, via the Universiti Tunku Abdul Rahman Research Fund (UTARRF), under project number IPSR/RMC/ UTARRF/2020-C1/H01. The authors are sincerely grateful for the funding so graciously provided.

\section{Declarations}

Conflict of interest The authors declare that they have no known competing financial interests or personal relationships that could have appeared to influence the work reported in this papery.

\section{References}

1. Stoll B, Andrade J, Cohen S, Brinkman G, Brancucci MartinezAnido C (2017) Hydropower modeling challenges. National Renewable Energy Lab.(NREL), Golden, CO (United States).

2. Liu X, Luo J (2019) A dynamic multi-objective optimization model with interactivity and uncertainty for real-time reservoir flood control operation. Appl Math Model. https://doi.org/10. 1016/j.apm.2019.05.009

3. Feng ZK, Niu WJ, Cheng CT (2018) Optimizing electrical power production of hydropower system by uniform progressive optimality algorithm based on two-stage search mechanism and uniform design. J Clean Prod. https://doi.org/10.1016/j.jclepro.2018. 04.134

4. Zeng Y, Wu X, Cheng C, Wang Y (2014) Chance-constrained optimal hedging rules for cascaded hydropower reservoirs. J Water Resour Plan Manag. https://doi.org/10.1061/(asce)wr. 1943-5452.0000427

5. Li YP, Huang GH, Chen X (2009) Multistage scenario-based interval-stochastic programming for planning water resources allocation. Stoch Environ Res Risk Assess. https://doi.org/10. 1007/s00477-008-0258-y

6. Liu P, Nguyen T-D, Cai X, Jiang X (2012) Finding multiple optimal solutions to optimal load distribution problem in hydropower plant 5:1413-1432 https://doi.org/10.3390/en5051413

7. Zeng X, Hu T, Cai X, Zhou Y, Wang X (2019) Improved dynamic programming for parallel reservoir system operation optimization. Adv Water Resour 131:103373. https://doi.org/10.1016/J. ADVWATRES.2019.07.003

8. Zhao T, Cai X, Lei X, Wang H (2012) Improved dynamic programming for reservoir operation optimization with a concave objective function. J Water Resour Plan Manag. https://doi.org/ 10.1061/(asce)wr.1943-5452.0000205

9. Li X, Wei J, Li T, Wang G, Yeh WWG (2014) A parallel dynamic programming algorithm for multi-reservoir system optimization. Adv Water Resour 67:1-15. https://doi.org/10.1016/J.ADVWA TRES.2014.01.002

10. Li C, Zhou J, Ouyang S, Ding X, Chen L (2014) Improved decomposition-coordination and discrete differential dynamic programming for optimization of large-scale hydropower system. 
Energy Convers Manag 84:363-373. https://doi.org/10.1016/J. ENCONMAN.2014.04.065

11. Lei X, Zhang J, Wang H, Wang M, Khu ST, Li Z, Tan Q (2018) Deriving mixed reservoir operating rules for flood control based on weighted non-dominated sorting genetic algorithm II. J Hydrol 564:967-983. https://doi.org/10.1016/J.JHYDROL.2018. 07.075

12. Jiang Z, Ji C, Qin H, Feng Z (2018) Multi-stage progressive optimality algorithm and its application in energy storage operation chart optimization of cascade reservoirs. Energy 148:309-323. https://doi.org/10.1016/J.ENERGY.2018.01.176

13. Wang S, Cao Y, Huang T, Chen Y, Li P, Wen S (2020) Sliding mode control of neural networks via continuous or periodic sampling event-triggering algorithm. Neural Netw 121:140-147. https://doi.org/10.1016/J.NEUNET.2019.09.001

14. Niu WJ, Feng ZK (2021) Evaluating the performances of several artificial intelligence methods in forecasting daily streamflow time series for sustainable water resources management. Sustain Cities Soc 64:102562. https://doi.org/10.1016/J.SCS.2020. 102562

15. Nguyen T, Nguyen G, Nguyen BM (2020) EO-CNN: An enhanced $\mathrm{CNN}$ model trained by equilibrium optimization for traffic transportation prediction. In: Procedia Computer Science 176:800-9. http://doi.org/10.1016/j.procs.2020.09.075

16. Yeniay Ö (2005) Penalty function methods for constrained optimization with genetic algorithms. Math Comput Appl. https:// doi.org/10.3390/mca10010045

17. Cassis JH, Schmit LA (1976) On implementation of the extended interior penalty function. Int J Numer Methods Eng. https://doi. org/10.1002/nme.1620100102

18. Liu J, Teo KL, Wang X, Wu C (2016) An exact penalty functionbased differential search algorithm for constrained global optimization. Soft Comput. https://doi.org/10.1007/s00500-015-1588-6

19. Snyman JA, Stander N, Roux WJ (1994) A dynamic penalty function method for the solution of structural optimization problems. Appl Math Model. https://doi.org/10.1016/0307-904X(94) 90307-7

20. Panda A, Pani S (2016) A symbiotic organisms search algorithm with adaptive penalty function to solve multi-objective constrained optimization problems. Appl Soft Comput J. https:// doi.org/10.1016/j.asoc.2016.04.030

21. Turgut MS, Turgut OE, Afan HA, El-Shafie A (2019) A novel master-slave optimization algorithm for generating an optimal release policy in case of reservoir operation. J Hydrol. https:// doi.org/10.1016/j.jhydrol.2019.123959

22. Hashimoto T, Stedinger JR, Loucks DP (1982) Reliability, resiliency, and vulnerability criteria for water resource system performance evaluation. Water Resour Res. https://doi.org/10.1029/ WR018i001p00014

23. Dobson B, Wagener T, Pianosi F (2019) An argument-driven classification and comparison of reservoir operation optimization methods. Adv Water Resour 128:74-86. https://doi.org/10. 1016/j.advwatres.2019.04.012

24. Latif SD, Marhain S, Hossain MS, Ahmed AN, Sherif M, Sefelnasr A, El-shafie A (2021) Optimizing the operation release policy using charged system search algorithm: a case study of klang gates dam. Malaysia Sustain. https://doi.org/10.3390/su131 15900

25. Sandoval-Solis S, McKinney DC, Loucks DP (2011) Sustainability index for water resources planning and management. J Water Resour Plan Manag. https://doi.org/10.1061/(asce)wr.1943-5452. 0000134

26. Emami M, Nazif S, Mousavi SF, Karami H, Daccache A (2021) A hybrid constrained coral reefs optimization algorithm with machine learning for optimizing multi-reservoir systems operation. J Environ Manag. https://doi.org/10.1016/j.jenvman. 2021.112250

27. Ehteram M, Banadkooki FB, Fai CM, Moslemzadeh M, Sapitang M, Ahmed AN, Irwan D, El-Shafie A (2021) Optimal operation of multi-reservoir systems for increasing power generation using a seagull optimization algorithm and heading policy. Energy Rep. https://doi.org/10.1016/j.egyr.2021.06.008

28. Chong KL, Lai SH, Ahmed AN, Wan Jaafar WZ, El-Shafie A (2021) Optimization of hydropower reservoir operation based on hedging policy using Jaya algorithm. Appl Soft Comput 106:107325. https://doi.org/10.1016/j.asoc.2021.107325

29. Niu WJ, Feng ZK, Liu S (2021) Multi-strategy gravitational search algorithm for constrained global optimization in coordinative operation of multiple hydropower reservoirs and solar photovoltaic power plants. Appl Soft Comput. https://doi.org/10. 1016/j.asoc.2021.107315

30. Kim YG, Sun BQ, Kim P, Jo MB, Ri TH, Pak GH (2021) A study on optimal operation of gate-controlled reservoir system for flood control based on PSO algorithm combined with rearrangement method of partial solution groups. J Hydrol. https://doi.org/10. 1016/j.jhydrol.2020.125783

31. Ahmadianfar I, Kheyrandish A, Jamei M, Gharabaghi B (2020) Optimizing operating rules for multi-reservoir hydropower generation systems: an adaptive hybrid differential evolution algorithm. Renew Energy. https://doi.org/10.1016/j.renene.2020.11. 152

32. Zhang Z, Qin H, Yao L, Liu Y, Jiang Z, Feng Z, Ouyang S (2020) Improved multi-objective moth-flame optimization algorithm based on R-domination for cascade reservoirs operation. J Hydrol 581:124431. https://doi.org/10.1016/J.JHYDROL.2019.124431

33. Liu D, Huang Q, Yang Y, Liu D, Wei X (2020) Bi-objective algorithm based on NSGA-II framework to optimize reservoirs operation. J Hydrol. https://doi.org/10.1016/j.jhydrol.2020.124830

34. Al-Aqeeli YH, Mahmood Agha OMA (2020) Optimal operation of multi-reservoir system for hydropower production using particle swarm optimization algorithm. Water Resour Manag 34:3099-3112. https://doi.org/10.1007/s11269-020-02583-8

35. Raso L, Bader J-C, Weijs S (2020) Reservoir operation optimized for hydropower production reduces conflict with traditional water uses in the Senegal River. J Water Resour Plan Manag 146:05020003. https://doi.org/10.1061/(asce)wr.1943-5452. 0001076

36. Paliwal V, Ghare AD, Mirajkar AB, Bokde ND, Lorenzo AEF (2020) Computer modeling for the operation optimization of mula reservoir, upper godavari basin, India, using the jaya algorithm. Sustain 12:1-21. https://doi.org/10.3390/su12010084

37. Moeini R, Babaei M (2020) Hybrid SVM-CIPSO methods for optimal operation of reservoir considering unknown future condition. Appl Soft Comput J. https://doi.org/10.1016/j.asoc.2020. 106572

38. Li X, Liu P, Gui Z, Ming B, Yang Z, Xie K, Zhang X (2020) Reducing lake water-level decline by optimizing reservoir operating rule curves: a case study of the three Gorges reservoir and the Dongting Lake. J Clean Prod. https://doi.org/10.1016/j.jclep ro.2020.121676

39. Tegegne G, Kim YO (2020) Representing inflow uncertainty for the development of monthly reservoir operations using genetic algorithms. J Hydrol. https://doi.org/10.1016/j.jhydrol.2020. 124876

40. Feng ZK, Liu S, Niu WJ, Li BJ, Wang WC, Luo B, Miao SM (2020) A modified sine cosine algorithm for accurate global optimization of numerical functions and multiple hydropower reservoirs operation. Knowl Based Syst. https://doi.org/10.1016/j. knosys.2020.106461

41. Asadieh B, Afshar A (2019) Optimization of water-supply and hydropower reservoir operation using the charged system search 
algorithm. Hydrology. https://doi.org/10.3390/hydrology6 010005

42. Feng ZK, Niu WJ, Zhang R, Wang S, Cheng CT (2019) Operation rule derivation of hydropower reservoir by k-means clustering method and extreme learning machine based on particle swarm optimization. J Hydrol 576:229-238. https://doi.org/10. 1016/j.jhydrol.2019.06.045

43. Meng X, Chang J, Wang X, Wang Y (2019) Multi-objective hydropower station operation using an improved cuckoo search algorithm. Energy 168:425-439. https://doi.org/10.1016/j. energy.2018.11.096

44. Ren K, Huang S, Huang Q, Wang H, Leng G, Cheng L, Fang W, Li P (2019) A nature-based reservoir optimization model for resolving the conflict in human water demand and riverine ecosystem protection. J Clean Prod. https://doi.org/10.1016/j.jclep ro.2019.05.221

45. Bai T, Wei J, Chang FJ, Yang W, Huang Q (2019) Optimize multi-objective transformation rules of water-sediment regulation for cascade reservoirs in the upper Yellow River of China. J Hydrol. https://doi.org/10.1016/j.jhydrol.2019.123987

46. Allawi MF, Jaafar O, Mohamad Hamzah F, Koting SB, Mohd NSB, El-Shafie A (2019) Forecasting hydrological parameters for reservoir system utilizing artificial intelligent models and exploring their influence on operation performance. Knowl Based Syst 163:907-926. https://doi.org/10.1016/j.knosys.2018.10.013

47. Yaseen ZM, Allawi MF, Karami H, Ehteram M, Farzin S, Ahmed AN, Koting SB, Mohd NS, Jaafar WZB, Afan HA, El-Shafie A (2019) A hybrid bat-swarm algorithm for optimizing dam and reservoir operation. Neural Comput Appl 31:8807-8821. https:// doi.org/10.1007/s00521-018-3952-9

48. Feng ZK, Niu WJ, Cheng CT (2018) Optimization of hydropower reservoirs operation balancing generation benefit and ecological requirement with parallel multi-objective genetic algorithm. Energy. https://doi.org/10.1016/j.energy.2018.04.075

49. Niu WJ, Feng ZK, Cheng CT, Wu XY (2018) A parallel multiobjective particle swarm optimization for cascade hydropower reservoir operation in southwest China. Appl Soft Comput J. https://doi.org/10.1016/j.asoc.2018.06.011

50. Hossain MS, Mohd Sidek LB, Marufuzzaman M, Zawawi MH (2018) Passive congregation theory for particle swarm optimization (PSO) an application in reservoir system operation Int J Eng Technol 7: 383-387 https://doi.org/10.14419/ijet.v7i4.35.22767

51. Ehteram M, Mousavi SF, Karami H, Farzin S, Emami M, Binti Othman F, Amini Z, Kisi O, El-Shafie A (2017) Fast convergence optimization model for single and multi-purposes reservoirs using hybrid algorithm. Adv Eng Informatics. https://doi.org/ 10.1016/j.aei.2017.04.001

52. Ehteram M, Karami H, Mousavi SF, El-Shafie A, Amini Z (2017) Optimizing dam and reservoirs operation based model utilizing shark algorithm approach. Knowl Based Syst 122:26-38. https:// doi.org/10.1016/j.knosys.2017.01.026

53. Bozorg-Haddad O, Janbaz M, Loáiciga HA (2016) Application of the gravity search algorithm to multi-reservoir operation optimization. Adv Water Resour. https://doi.org/10.1016/j.advwatres. 2016.11.001

54. Olofintoye O, Otieno F, Adeyemo J (2016) Real-time optimal water allocation for daily hydropower generation from the Vanderkloof dam, South Africa. Appl Soft Comput 47:119-129. https://doi.org/10.1016/j.asoc.2016.05.018

55. Li FF, Qiu J (2016) Multi-objective optimization for integrated hydro-photovoltaic power system. Appl Energy. https://doi.org/ 10.1016/j.apenergy.2015.09.018

56. Luo J, Qi Y, Xie J, Zhang X (2015) A hybrid multi-objective PSO-EDA algorithm for reservoir flood control operation. Appl
Soft Comput J 34:526-538. https://doi.org/10.1016/j.asoc.2015. 05.036

57. Yang T, Gao X, Sellars SL, Sorooshian S (2015) Improving the multi-objective evolutionary optimization algorithm for hydropower reservoir operations in the California Oroville-Thermalito complex. Environ Model Softw. https://doi.org/10.1016/j.envso ft.2014.11.016

58. He Y, Xu Q, Yang S, Liao L (2014) Reservoir flood control operation based on chaotic particle swarm optimization algorithm. Appl Math Model. https://doi.org/10.1016/j.apm.2014.02.030

59. Hossain MS, El-Shafie A (2014) Evolutionary techniques versus swarm intelligences: application in reservoir release optimization. Neural Comput Appl 24:1583-1594. https://doi.org/10. 1007/s00521-013-1389-8

60. Hossain MS, El-shafie A (2014) Performance analysis of artificial bee colony $(\mathrm{ABC})$ algorithm in optimizing release policy of Aswan High Dam. Neural Comput Appl 24:1199-1206. https:// doi.org/10.1007/s00521-012-1309-3

61. Sui X, Wu SN, Liao WG, Jia L, Jin TT, Zhang X (2013) Optimized operation of cascade reservoirs on Wujiang river during 2009-2010 drought in southwest China. Water Sci Eng. https:// doi.org/10.3882/j.issn.1674-2370.2013.03.007

62. Kurek W, Ostfeld A (2013) Multi-objective optimization of water quality, pumps operation, and storage sizing of water distribution systems. J Environ Manag. https://doi.org/10.1016/j.jenvm an.2012.11.030

63. Zhang R, Zhou J, Ouyang S, Wang X, Zhang H (2013) Optimal operation of multi-reservoir system by multi-elite guide particle swarm optimization. Int J Electr Power Energy Syst. https://doi. org/10.1016/j.ijepes.2012.11.031

64. Wu Y, Chen J (2013) Estimating irrigation water demand using an improved method and optimizing reservoir operation for water supply and hydropower generation: a case study of the Xinfengjiang reservoir in southern China. Agric Water Manag 116:110-121. https://doi.org/10.1016/j.agwat.2012.10.016

65. Huang YL, Huang GH, Liu DF, Zhu H, Sun W (2012) Simulation-based inexact chance-constrained nonlinear programming for eutrophication management in the Xiangxi bay of three gorges reservoir. J Environ Manag. https://doi.org/10.1016/j. jenvman.2012.04.037

66. Sedki A, Ouazar D (2012) Hybrid particle swarm optimization and differential evolution for optimal design of water distribution systems. Adv Eng Informatics. https://doi.org/10.1016/j.aei. 2012.03.007

67. Cioffi F, Gallerano F (2012) Multi-objective analysis of dam release flows in rivers downstream from hydropower reservoirs. Appl Math Model. https://doi.org/10.1016/j.apm.2011.09.077

68. Srivastav RK, Srinivasan K, Sudheer KP (2011) Simulation-optimization framework for multi-season hybrid stochastic models. J Hydrol. https://doi.org/10.1016/j.jhydrol.2011.04.031

69. Fu X, Li A, Wang L, Ji C (2011) Short-term scheduling of cascade reservoirs using an immune algorithm-based particle swarm optimization. Comput Math Appl. https://doi.org/10.1016/j. camwa.2011.07.032

70. Zhang J, Wu Z, Cheng CT, Zhang SQ (2011) Improved particle swarm optimization algorithm for multi-reservoir system operation. Water Sci Eng. https://doi.org/10.3882/j.issn.1674-2370. 2011.01.006

71. Wang KW, Chang LC, Chang FJ (2011) Multi-tier interactive genetic algorithms for the optimization of long-term reservoir operation. Adv Water Resour. https://doi.org/10.1016/j.advwa tres.2011.07.004

72. Rippl W (1883) The capacity of storage-reservoirs for waterslpply (including plate). Minutes Proc Inst Civ Eng. https://doi. org/10.1680/imotp.1883.21797 
73. Hazen A (1914) Storage to be provided in impounding municipal water supply. Trans Am Soc Civ Eng. https://doi.org/10.1061/ taceat.0002563

74. Loucks DP, Van Beek E (2017) Water resource systems planning and management: An introduction to methods, models, and applications. Springer.

75. Lee IM, Maass A, Hufschmidt MM, Dorfman R, Thomas HA, Marglin SA, Fair GM (1963) Design of water-resource systems. J Farm Econ. https://doi.org/10.2307/1236007

76. Vogel RM, Stedinger JR (1987) Generalized storage-reliabilityyield relationships. J Hydrol. https://doi.org/10.1016/00221694(87)90184-3

77. Vogel RM, Stedinger JR (1988) The value of stochastic streamflow models in overyear reservoir design applications. Water Resour Res. https://doi.org/10.1029/WR024i009p01483

78. Douglas EM, Vogel RM, Kroll CN (2002) Impact of streamflow persistence on hydrologic design. J Hydrol Eng. https://doi.org/ 10.1061/(asce)1084-0699(2002)7:3(220)

79. Celeste AB (2016) Managing spills in reservoir design optimisation models. Proc Inst Civ Eng Water Manag. https://doi.org/10. 1680/wama.14.00118

80. Hurtado JE, Barbat AH (1998) Monte carlo techniques in computational stochastic mechanics. Arch Comput Methods Eng. https://doi.org/10.1007/bf02736747

81. Celeste AB, Billib M (2009) Evaluation of stochastic reservoir operation optimization models. Adv Water Resour. https://doi. org/10.1016/j.advwatres.2009.06.008

82. Liu P, Li L, Chen G, Rheinheimer DE (2014) Parameter uncertainty analysis of reservoir operating rules based on implicit stochastic optimization. J Hydrol. https://doi.org/10.1016/j.jhydrol. 2014.04.012

83. Labadie JW (2004) Optimal operation of multireservoir systems: state-of-the-art review. J Water Resour Plan Manag. https://doi. org/10.1061/(asce)0733-9496(2004)130:2(93)

84. Derepasko D, Guillaume JHA, Horne AC, Volk M (2021) Considering scale within optimization procedures for water management decisions: Balancing environmental flows and human needs. Environ. Model. Softw. 139. https://doi.org/10.1016/j. envsoft.2021.104991

85. Houck MH, Cohon JL, ReVelle CS (1980) Linear decision rule in reservoir design and management: 6 . Incorporation of economic efficiency benefits and hydroelectric energy generation, Water Resour Res. https://doi.org/10.1029/WR016i001p00196

86. Loucks DP (1969) Erratum for "computer models for reservoir regulation.” J Sanit Eng Div. https://doi.org/10.1061/jsedai. 0000996

87. Nayak SC, Arora SR (1971) Optimal capacities for a multireservoir system using the linear decision rule. Water Resour Res. https://doi.org/10.1029/WR007i003p00485

88. Loucks DP, Dorfman PJ (1975) An evaluation of some linear decision rules in chance-constrained models for reservoir planning and operation. Water Resour Res. https://doi.org/10.1029/ WR011i006p00777

89. Hossain MS, El-shafie A (2013) Intelligent systems in optimizing reservoir operation policy: a review. Water Resour Manag 27:3387-3407. https://doi.org/10.1007/s11269-013-0353-9

90. Heydari M, Othman F, Qaderi K (2015) Developing optimal reservoir operation for multiple and multipurpose reservoirs using mathematical programming. Math Probl Eng. https://doi.org/10. $1155 / 2015 / 435752$

91. Urbanucci L (2018) Limits and potentials of mixed integer linear programming methods for optimization of polygeneration energy systems. Energy Procedia 148:1199-1205. https://doi.org/ 10.1016/J.EGYPRO.2018.08.021
92. Teegavarapu RSV, Simonovic SP (2000) Short-term operation model for coupled hydropower reservoirs. J Water Resour Plan Manag. https://doi.org/10.1061/(asce)0733-9496(2000)126:2(98)

93. Lee ES, Waziruddin S (1970) Applying gradient projection and conjugate gradient to the optimum operation of reservoirs. JAWRA J Am Water Resour Assoc. https://doi.org/10.1111/j. 1752-1688.1970.tb01616.x

94. Yeh HM, Lu CC (1978) Experimental studies on the degree of separation in thermal diffusion columns. Sep Sci Technol. https:// doi.org/10.1080/01496397808057089

95. Li JQ, Zhang YS, Ji CM, Wang AJ, Lund JR (2013) Large-scale hydropower system optimization using dynamic programming and object-oriented programming: the case of the Northeast China power grid. Water Sci Technol. https://doi.org/10.2166/ wst. 2013.528

96. Heidari M, Te CV, Kokotović PV, Meredith DD (1971) Discrete differential dynamic programing approach to water resources systems optimization. Water Resour Res. https:// doi.org/10.1029/WR007i002p00273

97. Te CV, Maidment DR, Tauxe GW (1975) Computer time and memory requirements for DP and DDDP in water resource systems analysis. Water Resour Res. https://doi.org/10.1029/ WR011i005p00621

98. Wang J, Zhang Y (2012) Short-term optimal operation of hydropower reservoirs with unit commitment and navigation. J Water Resour Plan Manag. https://doi.org/10.1061/(asce)wr. 1943-5452.0000142

99. Zheng J, Yang K, Hao Y (2012) Multi-objective decomposition-coordination for mix-connected hydropower system load distribution. Procedia Eng 28:210-213. https://doi.org/10. 1016/J.PROENG.2012.01.707

100. Feng ZK, Niu WJ, Cheng CT (2018) Optimizing electrical power production of hydropower system by uniform progressive optimality algorithm based on two-stage search mechanism and uniform design. J Clean Prod 190:432-442. https:// doi.org/10.1016/J.JCLEPRO.2018.04.134

101. Rostami M, Berahmand K, Nasiri E, Forouzande S (2021) Review of swarm intelligence-based feature selection methods Eng Appl Artif Intell 100. https://doi.org/10.1016/j.engappai. 2021.104210

102. Cantún-Avila KB, González-Sánchez D, Díaz-Infante S, Peñuñuri F (2021) Optimizing functionals using differential evolution. Eng Appl Artif Intell. https://doi.org/10.1016/j.engappai. 2020.104086

103. Husbands P, Copley P, Eldridge A, Mandelis J (2007) An introduction to evolutionary computing for musicians. In: Evolutionary Computer Music 1-27. https://doi.org/10.1007/ 978-1-84628-600-1_1

104. Holland JH (1992) Genetic algorithms. Sci Am. https://doi.org/ 10.1038/scientificamerican0792-66

105. Deb K, Pratap A, Agarwal S, Meyarivan T (2002) A fast and elitist multiobjective genetic algorithm: NSGA-II. IEEE Trans Evol Comput. https://doi.org/10.1109/4235.996017

106. Hobbie JG, Gandomi AH, Rahimi I (2021) A comparison of constraint handling techniques on NSGA-II. Arch Comput Methods Eng. https://doi.org/10.1007/s11831-020-09525-y

107. Tang Z, Hu X, Périaux J (2020) Multi-level hybridized optimization methods coupling local search deterministic and global search evolutionary algorithms. Arch Comput Methods Eng. https://doi.org/10.1007/s11831-019-09336-w

108. Ibrahim KSMH, Huang YF, Ahmed AN, Koo CH, El-Shafie A (2021) A review of the hybrid artificial intelligence and optimization modelling of hydrological streamflow forecasting. Alexandria Eng J. https://doi.org/10.1016/j.aej.2021.04.100 
109. Yazdi J, Moridi A (2018) Multi-objective differential evolution for design of cascade hydropower reservoir systems. Water Resour Manag. https://doi.org/10.1007/s11269-018-2083-5

110. Li Y, Li N, Gong G, Yan J (2021) A novel design of experiment algorithm using improved evolutionary multi-objective optimization strategy. Eng Appl Artif Intell. https://doi.org/10. 1016/j.engappai.2021.104283

111. Holland DE, Olesen RJ, Bevins JE (2021) Multi-objective genetic algorithm optimization of a directionally sensitive radiation detection system using a surrogate transport model. Eng Appl Artif Intell. https://doi.org/10.1016/j.engappai.2021. 104357

112. Kashani AR, Chiong R, Mirjalili S, Gandomi AH (2021) Particle swarm optimization variants for solving geotechnical problems: review and comparative analysis. Arch Comput Methods Eng. https://doi.org/10.1007/s11831-020-09442-0

113. Zheng F, Zecchin AC, Newman JP, Maier HR, Dandy GC (2017) An adaptive convergence-trajectory controlled ant colony optimization algorithm with application to water distribution system design problems. IEEE Trans Evol Comput. https://doi.org/10. 1109/TEVC.2017.2682899

114. Aydilek İB (2018) A hybrid firefly and particle swarm optimization algorithm for computationally expensive numerical problems. Appl Soft Comput J 66:232-249. https://doi.org/10.1016/j. asoc.2018.02.025

115. Dehghani M, Riahi-Madvar H, Hooshyaripor F, Mosavi A, Shamshirband S, Zavadskas EK, Chau KW (2019) Prediction of hydropower generation using Grey wolf optimization adaptive neuro-fuzzy inference system. Energies 12:1-20. https://doi.org/ $10.3390 / \mathrm{en} 12020289$

116. Liu J, Li D, Wu Y, Liu D (2020) Lion swarm optimization algorithm for comparative study with application to optimal dispatch of cascade hydropower stations. Appl Soft Comput J. https://doi. org/10.1016/j.asoc.2019.105974

117. Mirjalili S (2015) Moth-flame optimization algorithm: a novel nature-inspired heuristic paradigm. Knowl Based Syst. https:// doi.org/10.1016/j.knosys.2015.07.006

118. Meng Z, Li G, Wang X, Sait SM, Yildız AR (2021) A comparative study of metaheuristic algorithms for reliability-based design optimization problems. Arch Comput Methods Eng. https://doi. org/10.1007/s11831-020-09443-z

119. Rashedi E, Nezamabadi-pour H, Saryazdi S (2009) GSA: a gravitational search algorithm. Inf Sci (Ny). https://doi.org/10.1016/j. ins.2009.03.004

120. Moeini R, Soltani-nezhad M, Daei M (2017) Constrained gravitational search algorithm for large scale reservoir operation optimization problem. Eng Appl Artif Intell. https://doi.org/10.1016/j. engappai.2017.04.012

121. Khan TA, Ling SH (2021) A novel hybrid gravitational search particle swarm optimization algorithm. Eng Appl Artif Intell. https://doi.org/10.1016/j.engappai.2021.104263

122. Wang M, Zhang T, Wang P, Chen X (2020) An improved harmony search algorithm for solving day-ahead dispatch optimization problems of integrated energy systems considering timeseries constraints. Energy Build. https://doi.org/10.1016/j.enbui ld. 2020.110477

123. Feng ZK, Niu WJ, Liu S (2021) Cooperation search algorithm: a novel metaheuristic evolutionary intelligence algorithm for numerical optimization and engineering optimization problems. Appl Soft Comput. https://doi.org/10.1016/j.asoc.2020.106734

124. Zitar RA, Al-Betar MA, Awadallah MA, Doush IA, Assaleh K (2021) An intensive and comprehensive overview of JAYA algorithm, its versions and applications. Arch Comput Methods Eng 27:1-30. https://doi.org/10.1007/s11831-021-09585-8

125. Salcedo-Sanz S, Del Ser J, Landa-Torres I, Gil-López S, PortillaFigueras JA (2014) The coral reefs optimization algorithm: a novel metaheuristic for efficiently solving optimization problems. Sci World J. https://doi.org/10.1155/2014/739768

126. Kaveh A, Talatahari S (2010) A novel heuristic optimization method: charged system search. Acta Mech. https://doi.org/10. 1007/s00707-009-0270-4

127. Nguyen TT, Nguyen TT, Pham TD (2020) Applications of metaheuristic algorithms for optimal operation of cascaded hydropower plants. Neural Comput Appl. https://doi.org/10. 1007/s00521-020-05418-0

128. Nguyen TT, Nguyen TT, Pham TD (2021) Finding optimal solutions for reaching maximum power energy of hydroelectric plants in cascaded systems. J Ambient Intell Humaniz Comput. https:// doi.org/10.1007/s12652-021-03361-z

129. Chong KL, Lai SH, Ahmed AN, Jaafar WZW, Rao RV, Sherif M, Sefelnasr A, El-Shafie A (2021) Review on dam and reservoir optimal operation for irrigation and hydropower energy generation utilizing meta-heuristic algorithms. IEEE Access. https:// doi.org/10.1109/ACCESS.2021.3054424

130. Azad AS, Md MS, Watada J, Vasant P, Vintaned JAG (2020) Optimization of the hydropower energy generation using MetaHeuristic approaches: a review. Energy Rep 6:2230-2248. https://doi.org/10.1016/j.egyr.2020.08.009

131. Maier HR, Razavi S, Kapelan Z, Matott LS, Kasprzyk J, Tolson BA (2019) Introductory overview: optimization using evolutionary algorithms and other metaheuristics. Environ Model Softw 114:195-213. https://doi.org/10.1016/j.envsoft.2018.11.018

132. Sharma M, Kaur P (2021) A comprehensive analysis of natureinspired meta-heuristic techniques for feature selection problem. Arch Comput Methods Eng. https://doi.org/10.1007/ s11831-020-09412-6

133. Dahmani S, Yebdri D (2020) Hybrid algorithm of particle swarm optimization and grey wolf optimizer for reservoir operation management. Water Resour Manag 34:4545

134. Chaplot B (2021) Prediction of rainfall time series using soft computing techniques. Environ Monit Assess. https://doi.org/10. 1007/s10661-021-09388-1

135. Azamathulla H, Wu FC, Ghani AA, Narulkar SM, Zakaria NA, Chang CK (2008) Comparison between genetic algorithm and linear programming approach for real time operation. J Hydro Environ Res. https://doi.org/10.1016/j.jher.2008.10.001

136. Kaveh A, Bakhshpoori T (2019) Tug of war optimization algorithm In: Metaheuristics: outlines, MATLAB Codes and Examples. 123-135. Springer, Cham.

137. Al-Betar MA, Alyasseri ZA, Awadallah MA, Doush IA (2020) Coronavirus herd immunity optimizer (CHIO) https://doi.org/10. 1007/s00521-020-05296-6

138. Kaveh A, Ilchi Ghazaan M, Bakhshpoori T (2013) An improved ray optimization algorithm for design of truss structures. Period Polytech Civ Eng. https://doi.org/10.3311/PPci.7166

139. Li W, Wang GG, Gandomi AH (2021) A survey of learningbased intelligent optimization algorithms. Arch Comput Methods Eng. https://doi.org/10.1007/s11831-021-09562-1

140. Tan ML, Ibrahim AL, Yusop Z, Chua VP, Chan NW (2017) Climate change impacts under CMIP5 RCP scenarios on water resources of the Kelantan River Basin. Malaysia Atmos Res. https://doi.org/10.1016/j.atmosres.2017.01.008

141. Homsi R, Shiru MS, Shahid S, Ismail T, Bin HS, Al-Ansari N, Chau KW, Yaseen ZM (2020) Precipitation projection using a CMIP5 GCM ensemble model: a regional investigation of Syria. Eng Appl Comput Fluid Mech. https://doi.org/10.1080/19942 060.2019 .1683076

Publisher's Note Springer Nature remains neutral with regard to jurisdictional claims in published maps and institutional affiliations. 